\section{Abstract}

\title{
Wash wave effects on ships moored in ports
}

\author{
Liang Li, Zhiming Yuan*, Yan Gao \\ Department of Naval Architecture, Ocean and Marine Engineering, University of Strathclyde, 100 Montrose Street, \\ Glasgow, G4 OLZ, UK \\ *Corresponding author: zhiming.yuan@strath.ac.uk.
}

A ship moored in a port is subjected to both the sea waves and the wash waves produced by nearby passing ships. A hybrid numerical model is proposed to estimate the transient response of a moored ship exposed to the two types of waves. The hybrid method is based on the combination of 3-D Rankine source method and impulse response theory. The 3-D Rankine source method is applied to address the wash waves and the wave-structure interactions. The transient response is subsequently simulated in time-domain with the impulse response theory. The transient effect produced by the wash wave impact loads is found to be dependent on the sea waves induced response. The transient effect becomes less significant when the sea waves induced response is strong and vice versa. Besides, the propagation distance of wash waves has a limited influence on the transient response due to the dissipation feature of the divergent wash waves. The transient response in stochastic sea waves is also investigated, which is dominated by the resonant frequency, the sea wave frequency and the wash wave varying frequency. Keyword: Wash waves; Sea waves; Transient response; Wave impact loads; Moored ship; Port

\section{Introduction}

A ship moored in a port is subjected to complicated external loads, which may induce strong motions of the moored ship. When the motions become very large, marine operations must be terminated and the downtime will be consequently increased. For the safety of operation, the motions of a moored ship in a port should be investigated carefully.

Kwak et al. [1] proposed a computational method to estimate the motions of a moored ship taking into consideration of the harbour resonance. The simulation results with and without harbour resonance were compared. Sakakibara and Kubo [2] investigated the low-frequency motions of a moored ship inside ports induced by the harbour resonance. Rosa-Santos et al. [3] examined how the type of fender influenced the mooring tension of a moored ship at an exposed port terminal. Xiong et al. [4] studied the shallow water effect on the motions of a moored barge with both numerical and experimental methods. The second order difference frequency force was incorporated to capture the long-period motions of the barge realistically. A critical depth for shallow water effect was clarified. In a port or coastal region, the sea waves will propagate from deep water to shallow water and the port geometry also has an influence on the wave propagation. A very popular method for wave propagation is the 
combination of a phase resolving wave model and a boundary element method. Bingham [5] came up with a new computational technique to predict the wave-induced motion of a moored ship. Modified Boussinesq theory was used to assess the transformation of the waves when they propagate from deep water zone to the port. The corrected waves were subsequently used to obtain the hydrodynamic interactions. Van der Molen and Wenneker [6] developed a combination of the Boussinesq-type wave model and the time-domain panel model to predict the motions of a moored ship in open sea. The calculation procedures were very like those applied in [5]. However, the effect of port boundaries (which cause wave reflection) was not considered in their works. Jiang et al. [7] combined the Boussinesq's equations and the slender-body theory to investigate the wake produced by a ship. The Boussinesq's equations were used for the far-field flow and the slender-body theory was applied for the near-field flow. They showed that the wash wave pattern depends a lot on the ship speed and bottom topography.

Apart from the incident sea waves, a passing ship also causes the moored ship to move. Vantorre et al. [8] carried out model tests to investigate the hydrodyanmic interaction between a moored ship and a passing ship during overtaking operation. A model test program was launched by Mousaviraad et al. [9] to investigate the effect of configurations, speed and heading angle on ship-to-ship interactions in calm water and waves. Both works proved that the moored ship is subject to considerable hydrodynamic loads due to the passing effect induced by the other ship. Alongside with model test method, analytical and empirical approaches have been developed as well, most of which are based on the slender-body theory. Brix [10] proposed an empirical formula to estimate the maximum values of the longitudinal and the transverse forces acting on a moored ship induced by another passing ship,which is not applicable to very high speed problem. Wang [11] developed an analytical solution to the unsteady interaction of two slender floating bodies with a propagation angle of yaw. Nevertheless, the free surface disturbance was not considered in his model. Apart from the model test and the analytical approaches, the numerical simulation method is also adopted by researchers in the study of ship-to-ship interaction. Pinkster [12] studied the wash effects of passing ships in ports. The reflection of long waves due to the interaction of wash wave and geometry of the port was considered. Yuan et al. [13] proposed a decoupled numerical model to assess the ship-to-ship interaction during overtaking operation in shallow water. A modified Sommerfeld radiation condition taking into account the Doppler shift effect was proposed and thereby their model is applicable to very low speed problem where the scattered wave could propagate in front of the advancing ship. Xu and Zou [14] used a high-order panel method to predict hydrodynamic force on a moored ship induced by a passing ship in shallow water. Calculations were conducted with different water depths and lateral distances between the two ships. An advantage of their method is that the numerical damping caused by the configuration of meshes is limited so that only a few meshes were distributed on the water surface.

Until now, the majority of the studies on the response of a moored ship induced by a passing ship are based on the assumption that the two ships are arranged in close proximity and the forward speed is 
very low. It inherently implies that the moored ship's motions are mainly dominated by the local wave field. As well-known [6], the wash waves produced by an advancing ship with high speed can travel a long distance with little dissipation (see Fig. 1) so that the moored ship will be subjected to substantial wash wave force even if the passing ship is far away as long as the forward speed is high enough. Nevertheless, few studies have been conducted regarding the response of a moored ship produced by the wash waves. In this work, a hybrid numerical model is developed to investigate the transient response of a ship moored in a port when a ship is passing by with high forward speed. It is assumed that the wash waves and the incident sea waves are independent from each other so that they can be addressed separately. The wash waves and their impact loads on the moored ship are simulated with a 3-D boundary element method based on the Rankine Green function. Subsequently, a hydro-mooring coupled analysis is performed in time-domain to investigate the transient response of the ship under the joint action of wash waves and sea waves. This paper is organized as following: Firstly, the detailed setup of the hybrid model will be presented and followed by the description of the problem concerned. Subsequently, validation against analytical approximation and published simulation results will be conducted. Finally, this work investigates the transient responses of a moored ship under joint action of the sea waves and the wash waves induced by a passing ship.

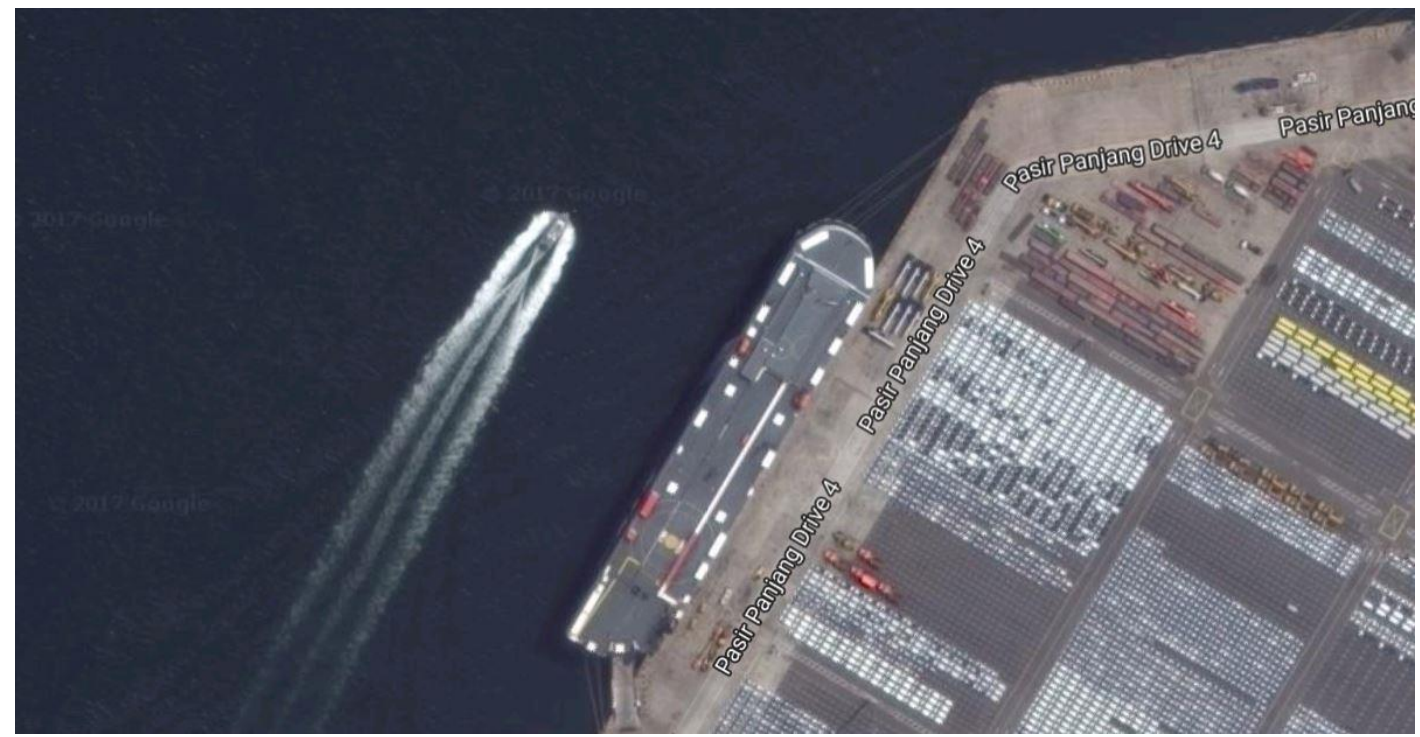

Fig. 1. The wash waves produced by an advancing ship. (Google Map. https://www.google.co.uk/maps/@1.2841423,103.7517161,382m/data=!3m1!1e3?hl=zh-CN)

\section{Hybrid numerical model}

A hybrid numerical model based on the combination of 3-D Rankine source method [15] and impulse response theory [16] is developed to simulate dynamic response of the moored ship subjected to sea waves and wash waves. Fig. 2 displays the calculation procedure of the hybrid numerical model. It is assumed that the wash waves and the sea waves are decoupled so that they can be addressed separately. The 3-D Rankine source method is used to address the wash waves and the wave-structure 
97 interaction. Afterwards, the transient response of the moored ship under the joint action of the wash 98 waves and the sea waves is simulated with the impulse response theory.

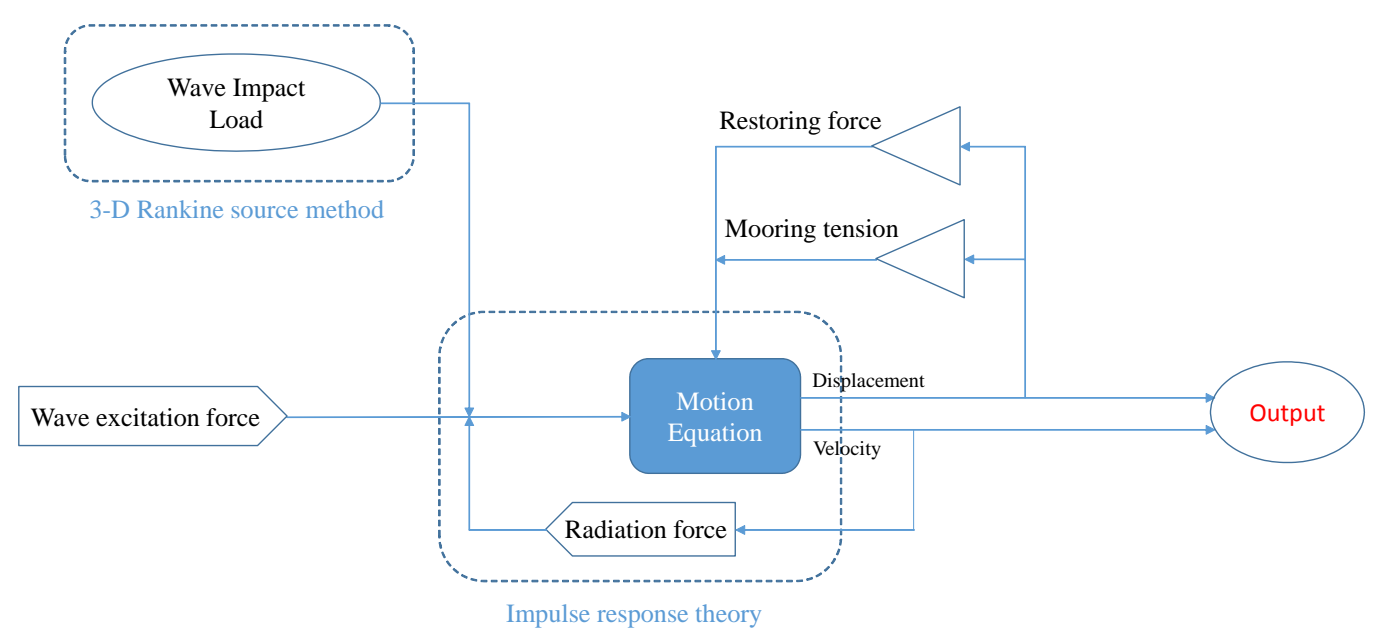

99

Fig. 2. Sketch of the hybrid numerical model.

\subsection{3-D Rankine source method}

\subsubsection{Coordinate system}

As shown in Fig. 9, two coordinate systems are selected. The first coordinate system $O-X Y Z$ is a fixed coordinate, with the positive $Z$ axis pointing upwards. The origin $O$ is located exactly on the calm free surface and right above the CoG (centre of gravity) of the motionless ship. The second coordinate system $O_{0}-X_{0} Y_{0} Z_{0}$ is fixed to the passing ship with the positive $Z_{0}$ axis pointing upwards as well.

\subsubsection{Boundary value problem}

Assuming that the fluid is ideal, the velocity potential is used to describe the flow at any point within the fluid domain. It is well-known that the velocity potential satisfies the Laplace equation in the fluid domain, and therefore the calculation of velocity potential is transformed to the boundary value problem. Fig. 3 illustrates the boundary of the fluid domain. The length of the fluid domain is $600 \mathrm{~m}$ and the width is $260 \mathrm{~m}$. The vertical size, namely the water depth, is $10 \mathrm{~m}$. 


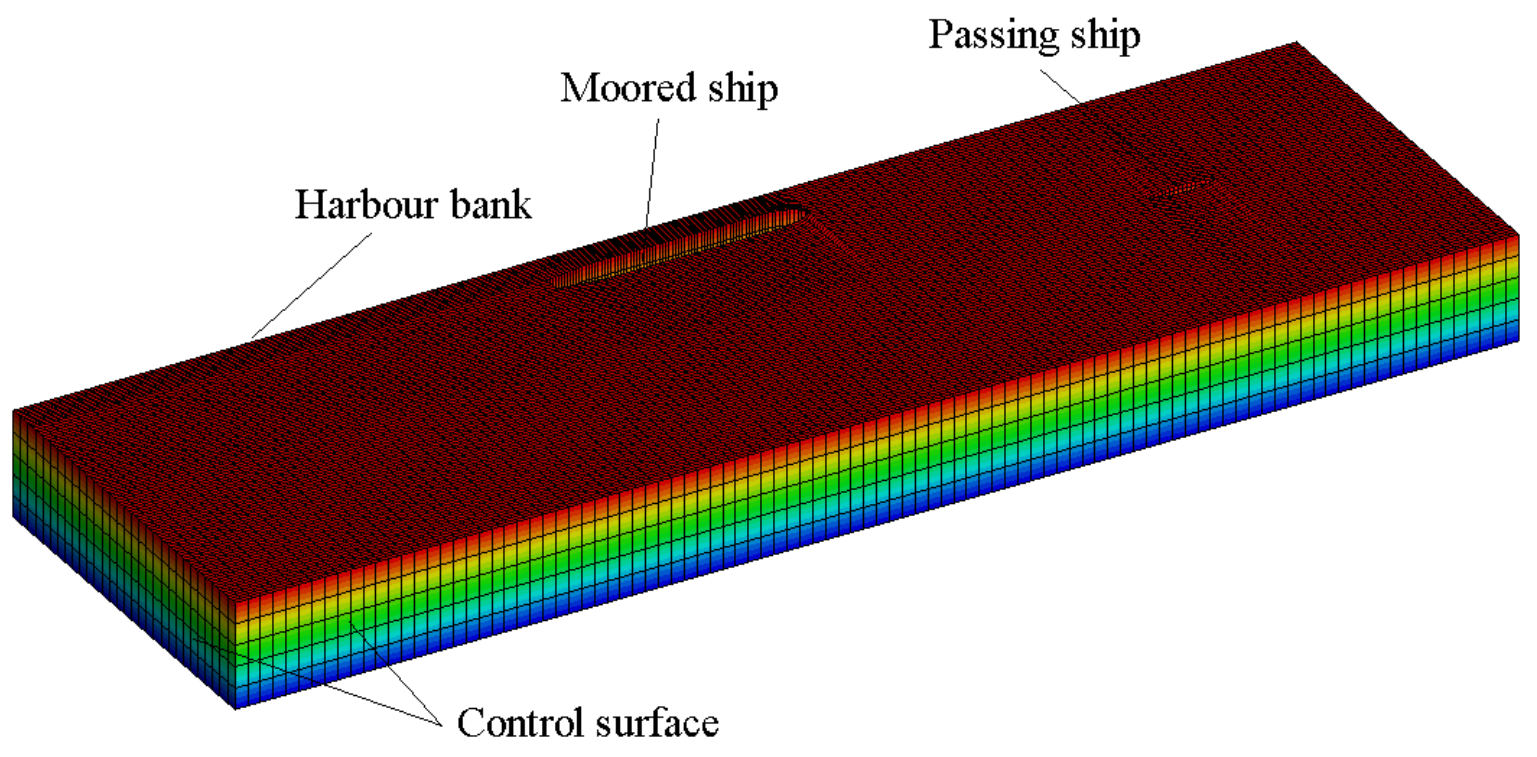

Fig. 3. Boundary of fluid domain.

The wash wave potential $\varphi_{S}$ is dealt with in the body-fixed coordinate system $O_{0}-X_{0} Y_{0} Z_{0}$ that moves together with the passing ship.

$$
\begin{aligned}
& \nabla^{2} \varphi_{s}=0 \text {,in fluid domain } \\
& \frac{\partial \varphi_{s}}{\partial \boldsymbol{n}}=u n_{1} \text {, on passing ship } \\
& \frac{\partial \varphi_{s}}{\partial \boldsymbol{n}}=0, \text { on moored ship }
\end{aligned}
$$

$$
\begin{aligned}
& u^{2} \frac{\partial^{2} \varphi_{s}}{\partial x^{2}}+g \frac{\partial \varphi_{s}}{\partial z}=0, \text { on } z_{0}=0 \\
& \frac{\partial \varphi_{s}}{\partial \boldsymbol{n}}=0, \text { on harbour bank } \\
& \frac{\partial \varphi_{s}}{\partial \boldsymbol{n}}=0, \text { on } z_{0}=-H
\end{aligned}
$$

where $u$ is the forward speed of the passing ship. $\boldsymbol{n}=\left(n_{1}, n_{2}, n_{3}\right)$ is the unit normal vector inward on the ship body surface and $H$ is the water depth. Once the wash wave potential $\varphi_{s}$ is obtained, the wash wave impact loads acting on the moored ship are given by

$$
\begin{aligned}
& F_{i}=\iint_{S} p n_{i} d S \\
& p=-\rho\left(\frac{\partial \varphi_{s}}{\partial t}-u \frac{\partial \varphi_{s}}{\partial x}\right), i=1,2, \ldots, 6
\end{aligned}
$$

in which $\rho$ is the water density and $S$ is the wetted surface of the moored ship. The generalized normal vector $n_{i}$ is defined as

$$
n_{i}=\left\{\begin{array}{c}
\boldsymbol{n}, i=1,2,3 \\
\boldsymbol{r} \times \boldsymbol{n}, i=4,5,6
\end{array}\right.
$$

where $\boldsymbol{r}=(x, y, z)$ is the position vector. 
The radiation/diffraction potentials of sea waves are addressed in the global coordinate system $O$ $X Y Z$. The hydrodynamic interaction between the moored ship and the passing ship is neglected due to

128 the long distance. The boundary value formula of radiation potential is given by

$$
\begin{aligned}
& \nabla^{2} \varphi_{j}=0, \text { in fluid domain } \\
& \frac{\partial \varphi_{j}}{\partial \boldsymbol{n}}=-i \omega n_{j}, \text { on moored ship } \\
& -\omega^{2} \varphi_{j}+g \frac{\partial \varphi_{j}}{\partial z}=0, \text { on } z=0
\end{aligned}
$$

$$
\begin{aligned}
& \frac{\partial \varphi_{j}}{\partial \boldsymbol{n}}=0, \text { on harbour bank } \quad, j=1,2, \ldots, 6 \\
& \frac{\partial \varphi_{j}}{\partial \boldsymbol{n}}=0, \text { on } z=-H \\
& \frac{\partial \varphi_{j}}{\partial \boldsymbol{n}}-i k \varphi_{j}=0, \text { on the control surface }
\end{aligned}
$$

with $\omega$ is the frequency of the incident sea wave and $k$ is the wave number.

The boundary value formula of diffraction potential is given by

$$
\begin{aligned}
& \nabla^{2} \varphi_{7}=0, \text { in the fluid domain } \\
& \frac{\partial \varphi_{7}}{\partial \boldsymbol{n}}=-\frac{\partial \varphi_{0}}{\partial \boldsymbol{n}}, \text { on moored ship } \\
& -\omega^{2} \varphi_{7}+g \frac{\partial \varphi_{7}}{\partial z}=0, \text { on } z=0
\end{aligned}
$$

$$
\frac{\partial \varphi_{7}}{\partial \boldsymbol{n}}=0, \text { on harbour bank }
$$

$$
\begin{aligned}
& \frac{\partial \varphi_{7}}{\partial \boldsymbol{n}}=0, \text { on } z=-H \\
& \frac{\partial \varphi_{7}}{\partial \boldsymbol{n}}-i k \varphi_{7}=0, \text { on the control surface }
\end{aligned}
$$

where the incident sea wave potential is given by

$$
\varphi_{0}=\frac{g}{i \omega} \cdot \frac{\cosh (k z+k H)}{\cosh (k H)} \cdot e^{-i k(x \cos \beta+y \sin \beta)}
$$

Once the radiation potential and the diffraction potential of the moored ship are obtained, the sea wave excitation forces $f_{j}^{e x t}$, the added mass $\mu_{i j}$ and the potential damping $\lambda_{i j}$ are given by

$$
f_{j}^{e x t}=\operatorname{Re}\left[\rho i \omega \iint_{S}\left(\varphi_{0}+\varphi_{7}\right) e^{-i \omega t} n_{j} d S\right], j=1,2, \ldots, 6
$$

$$
\begin{gathered}
\mu_{i j}=\operatorname{Re}\left[\rho \omega \iint_{S} \varphi_{j} n_{i} d S\right], i, j=1,2, \ldots, 6 \\
\lambda_{i j}=\operatorname{Im}\left[\rho \iint_{S} \varphi_{j} n_{i} d S\right], i, j=1,2, \ldots, 6
\end{gathered}
$$


As shown in Eq. (1), the second derivate of the wash wave potential appears in the free surface boundary condition, which should be handled with special care. Longuet-Higgins and Cokelet [17] found that the analytical expression of the second derivate term could lead to a saw-toothed wave pattern. Similar problem was reported by $\mathrm{Xu}$ and Yue [18] as well. Consequently, the second-order upwind difference scheme proposed by Bunnik [19] is used to represent the second derivate term

$$
\frac{\partial^{2} \varphi_{s}}{\partial x^{2}}\left(\boldsymbol{r}_{i}\right)=\frac{1}{\Delta x_{i}^{2}}\left[\frac{1}{2} \varphi\left(\boldsymbol{r}_{i+4}\right)-2 \varphi\left(\boldsymbol{r}_{i+3}\right)+\frac{11}{2} \varphi\left(\boldsymbol{r}_{i+2}\right)-6 \varphi\left(\boldsymbol{r}_{i+1}\right)+\frac{9}{4} \varphi\left(\boldsymbol{r}_{i}\right)\right]
$$

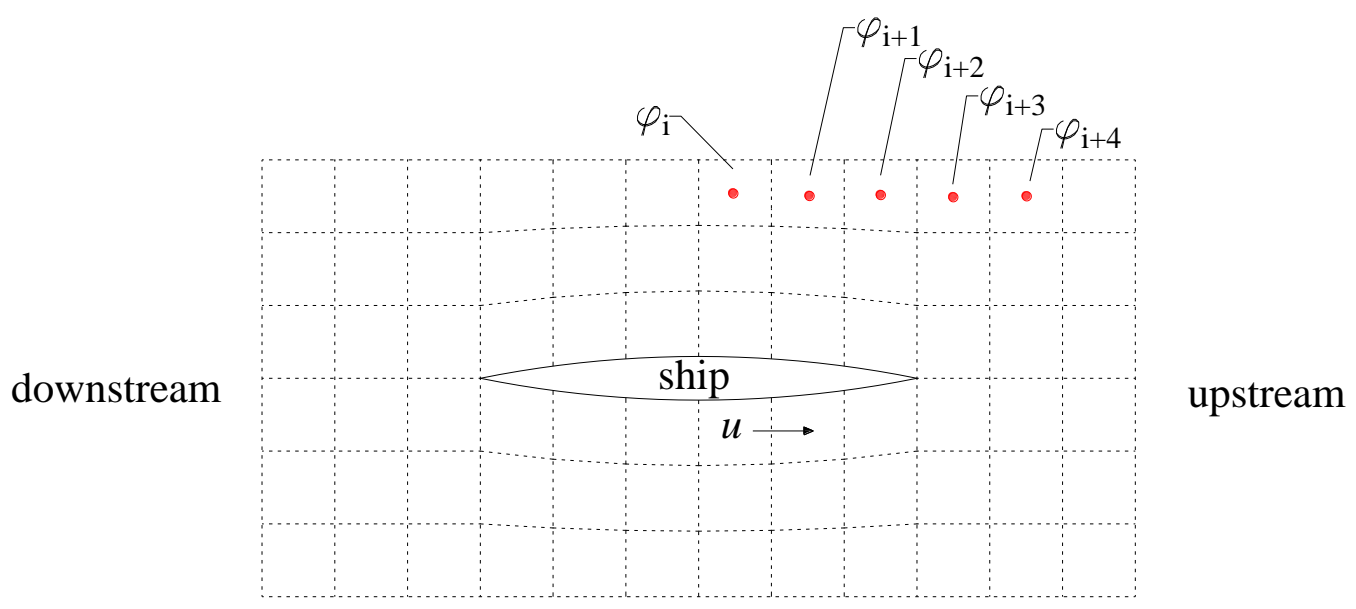

Fig. 4. Second-order upwind difference scheme.

In principle, it is required that the Rankine source should be distributed exactly on the undisturbed free surface. Nevertheless, a desingularized method is commonly used which raises the elements on free water surface a short distance upwards (see Fig. 5) [20]. Meanwhile, the collocation points, where boundary condition is satisfied, still stay exactly on the calm free surface. A raised distance $\nabla z=\sqrt{S}$ suggested by Zhang et al. [21] is selected, where $S$ is the local element area.

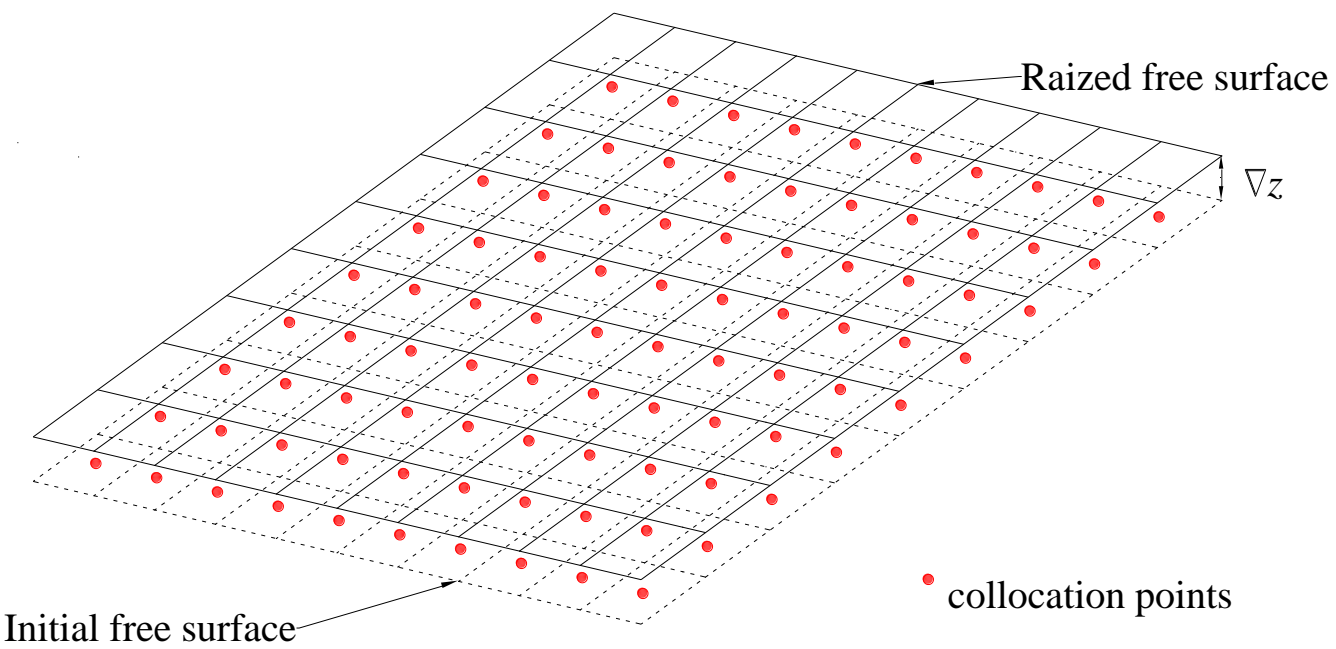

Fig. 5. Raise of the free surface. 
In the present study, the linear Rankine source is used. Assuming that the source strength $\sigma(\xi)$ is uniformly distributed across the panel ( $\xi$ is the positon vector of point on the entire fluid boundary $S_{\text {total }}$ ), the velocity potential at point $\boldsymbol{r}$ within the fluid domain is expressed as

$$
\varphi(\boldsymbol{r})=\iint_{S_{\text {total }}} \sigma(\boldsymbol{\xi}) G(\boldsymbol{r}, \boldsymbol{\xi}) d S
$$

where $G(\boldsymbol{r}, \boldsymbol{\xi})$ is the Rankine-type Green function

$$
G(\boldsymbol{r}, \boldsymbol{\xi})=\frac{1}{\sqrt{|\boldsymbol{r}-\boldsymbol{\xi}|^{2}}}
$$

Combining Eq. (11) into the boundary value formulas, the source strength can be calculated and the potential at any point of the fluid domain is known.

\subsubsection{Re-meshing algorithm}

Ship passing ship is a moving boundary problem by nature. It requires update of the free surface truncation at each time step and the boundary value problem should be solved alongside with the update of mesh distribution on the free surface. A re-meshing algorithm based on the concepts of local mesh and global mesh is developed. The local mesh is body-fixed and moves with the ship throughout the passing process. Comparatively, the global mesh can be understood as a kind of background mesh, which is fixed to the selected coordinate system. The essential idea of the re-meshing algorithm is to use the local mesh to overlap the global mesh and the complicated re-meshing problem will be converted in this way to a simple connection operation.

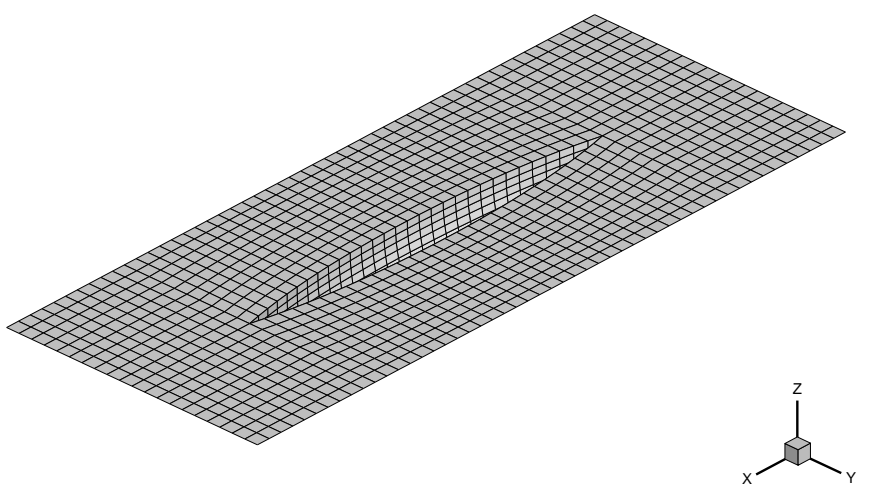

Fig. 6. Local mesh. 


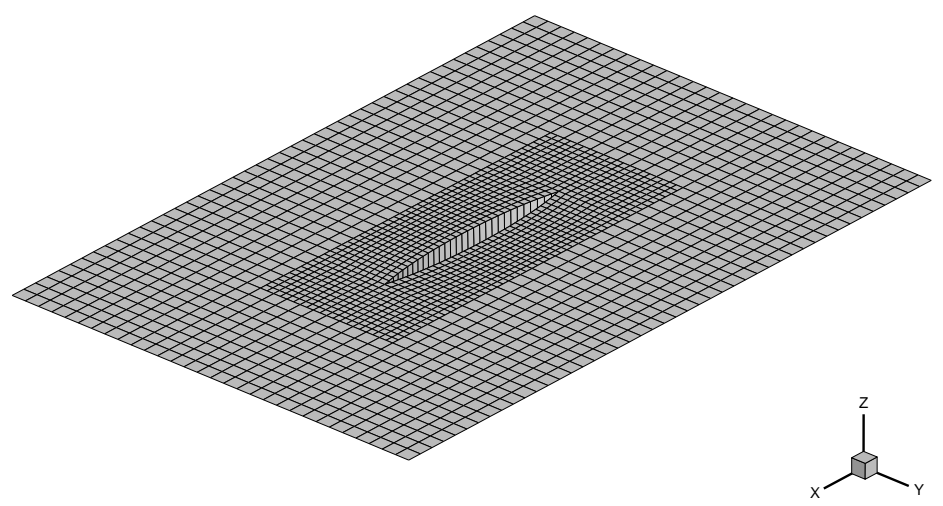

174

175

176

177

178

179

180

181

182

190

Fig. 7. Merged mesh

\subsection{Impulse response theory}

The time-domain motion equation of a moored ship in waves is given by,

$$
\sum_{j=1}^{6}\left[\left(M_{i j}+\mu_{i j}(\infty)\right) \ddot{x}_{j}(t)+\int_{0}^{t} h_{i j}(t-\tau) \dot{x}_{j}(t) d \tau+C_{i j} x_{j}(t)\right]=f_{i}(t), i=1,2, \ldots, 6
$$

where $M$ is the mass matrix of the moored ship, $\mu(\infty)$ is the added mass matrix at infinite frequency, $x(t), \dot{x}(t)$ and $\ddot{x}(t)$ are the displacement, velocity and acceleration vectors, $C$ is the static restoring stiffness matrix, $h_{i j}(t)$ is known as the retardation function, which can be represented by either added mass or potential damping

$$
h_{i j}(t)=\frac{2}{\pi} \int_{0}^{\infty} \mu_{i j}(\omega) \cos (\omega t) d \omega=\frac{2}{\pi} \int_{0}^{\infty} \frac{\lambda_{i j}}{\omega}(\omega) \sin (\omega t) d \omega
$$

$f_{i}(t)$ are the resultant external forces, including the wash wave impact loads, the linear sea wave excitation forces and the hawser-fender tension forces. The wash wave impact loads and the sea wave excitation forces are addressed with the 3-D Rankine source method (Eq. (2) and Eq. (7)).

The fender is simulated numerically with a linear-spring model, which is assumed to possess restoring stiffness on sway and roll modes merely. The restoring stiffness matrix of the fender is given by

$$
K=\left[\begin{array}{cccccc}
0 & 0 & 0 & 0 & 0 & 0 \\
0 & K_{22}(y) & 0 & 0 & 0 & 0 \\
0 & 0 & 0 & 0 & 0 & 0 \\
0 & 0 & 0 & -K_{22}(y) \cdot 0.5 m & 0 & 0 \\
0 & 0 & 0 & 0 & 0 & 0 \\
0 & 0 & 0 & 0 & 0 & 0
\end{array}\right], K_{22}(y)=\left\{\begin{array}{c}
0 \mathrm{kN} / \mathrm{m}, y<0 \\
3800 \mathrm{kN} / \mathrm{m}, y>0
\end{array}\right.
$$

The hawser is simulated with a lumped-mass approach. As shown in Fig. 8, the hawser is divided into a series of evenly-sized segments, which are represented by connected nodes and spring and damper systems. Each segment is divided into two components and the properties are assigned and lumped to 
194 the two nodes at each end of that segment, respectively. The connections between the adjacent nodes

195 are represented by damper-spring systems. In this study, the lumped-mass approach merely models the 196 axial properties of the mooring lines while the torsional and bending properties are neglected. The wave

197 kinematics effect and any other external loads are also ignored in the lumped-mas model. Details of the 198 basic equations and the calculation procedures can be found in [22].

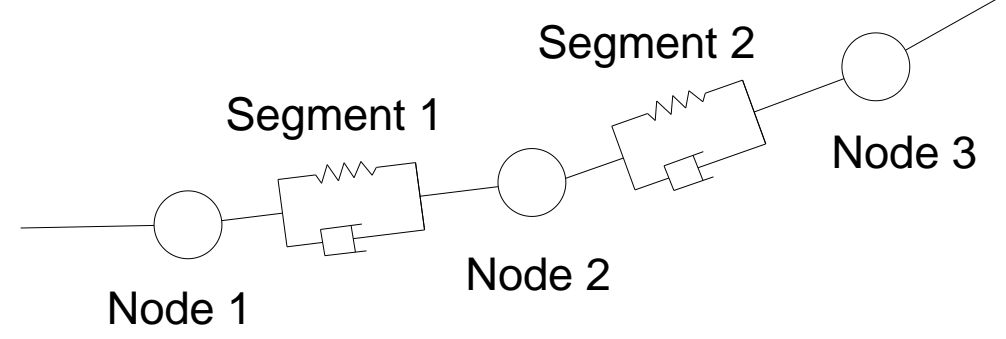

199

200

201

202

203

204

205

Fig. 8. Lumped-mass model of hawser.

\section{Model description}

As shown in Fig. 9, a ship is passing by a moored ship with high speed. The movement of the passing ship sets up wash waves emanating from the bow and stern of the ship which consists of the transverse waves and the divergent waves. Meanwhile, the ship is also subjected to the sea waves. The water depth is set to $10 \mathrm{~m}$.
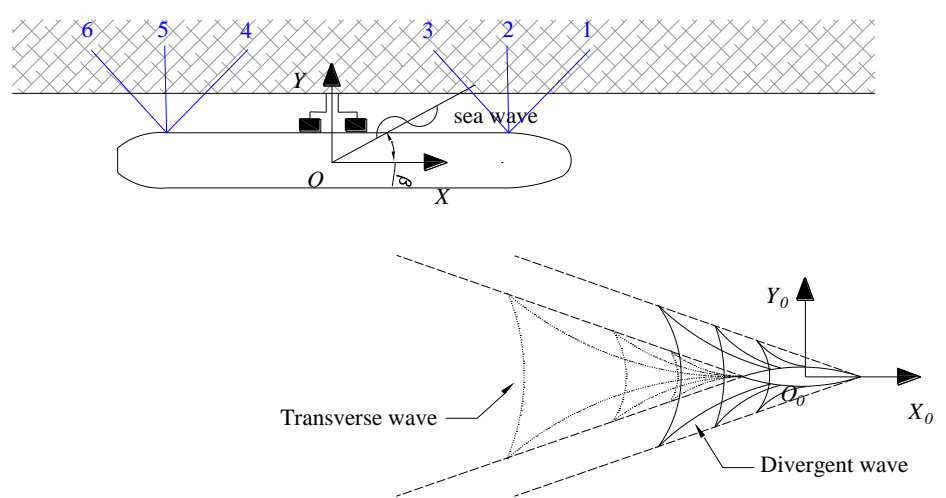

Fig. 9. Sketch of a ship passing a ship moored at port. 
The passing ship is a Wigley vessel with the main dimensions listed in Table 1. It is enforced to travel along positive $X$ direction with a constant forward speed. No oscillating motions of the passing ship are allowed. The lateral distance $d t$ between the two ships is set to a large value. Considering the large lateral distance, the hydrodynamic interaction of the two ships is neglected.

Table 1 Main dimensions of the passing ship.

\begin{tabular}{ll}
\hline Parameter & Value \\
\hline Length $\left(L_{1}\right)$ & $30 \mathrm{~m}$ \\
Breath $\left(B_{1}\right)$ & $6 \mathrm{~m}$ \\
Draft $\left(D_{1}\right)$ & $1.875 \mathrm{~m}$ \\
\hline
\end{tabular}

The ship is moored in the port through the hawser-fender system. The gap width between the moored ship and the port bank is $13 \mathrm{~m}$. The main dimensions of the moored ship are listed in Table 2. Properties of the hawser lines are shown in Table 3.

218 Table 2 Main dimensions of the moored ship.

\begin{tabular}{ll}
\hline Parameter & Value \\
\hline Length $\left(L_{2}\right)$ & $120 \mathrm{~m}$ \\
Breath $\left(B_{2}\right)$ & $14 \mathrm{~m}$ \\
Draft $\left(D_{2}\right)$ & $4.5 \mathrm{~m}$ \\
Centre of gravity $(\mathrm{CoG})$ below still water surface & $0.5 \mathrm{~m}$ \\
Displacement $(V)$ & $7,773 \mathrm{~m}^{3}$ \\
Roll inertia moment $\left(I_{\mathrm{xx}}\right)$ & $2.35 \times 10^{7} \mathrm{~kg} \cdot \mathrm{m}^{2}$ \\
Pitch inertia moment $\left(I_{\mathrm{yy}}\right)$ & $1.04 \times 10^{10} \mathrm{~kg} \cdot \mathrm{m}^{2}$ \\
Yaw inertia moment $\left(I_{\mathrm{zz}}\right)$ & $1.17 \times 10^{10} \mathrm{~kg} \cdot \mathrm{m}^{2}$ \\
\hline
\end{tabular}

Table 3 Properties of the hawser lines.

\begin{tabular}{|c|c|c|c|c|c|c|}
\hline & Diameter & Density & EA & $\begin{array}{l}\text { Upstretched } \\
\text { length }\end{array}$ & Fairlead & Anchor \\
\hline Hawser 1 & & & & $28.8 \mathrm{~m}$ & $(50 \mathrm{~m}, 7 \mathrm{~m} 2 \mathrm{~m})$ & $(74 \mathrm{~m}, 24 \mathrm{~m} 1 \mathrm{~m})$ \\
\hline Hawser 2 & & & & $16.8 \mathrm{~m}$ & $(50 \mathrm{~m}, 7 \mathrm{~m} 2 \mathrm{~m})$ & $(50 \mathrm{~m}, 24 \mathrm{~m} 1 \mathrm{~m})$ \\
\hline Hawser 3 & & & & $28.8 \mathrm{~m}$ & $(50 \mathrm{~m}, 7 \mathrm{~m} 2 \mathrm{~m})$ & $(26 \mathrm{~m}, 24 \mathrm{~m} 1 \mathrm{~m})$ \\
\hline Hawser 4 & $0.052 \mathrm{~m}$ & $10.3 \mathrm{~kg}$ & $3120 \mathrm{kN}$ & $28.8 \mathrm{~m}$ & $(-50 \mathrm{~m}, 7 \mathrm{~m} 2 \mathrm{~m})$ & $(-26 \mathrm{~m}, 24 \mathrm{~m} 1 \mathrm{~m})$ \\
\hline Hawser 5 & & & & $16.8 \mathrm{~m}$ & $(-50 \mathrm{~m}, 7 \mathrm{~m} 2 \mathrm{~m})$ & $(-50 \mathrm{~m}, 24 \mathrm{~m} 1 \mathrm{~m})$ \\
\hline Hawser 6 & & & & $28.8 \mathrm{~m}$ & $(-50 \mathrm{~m}, 7 \mathrm{~m} 2 \mathrm{~m})$ & $(-74 \mathrm{~m}, 24 \mathrm{~m} 1 \mathrm{~m})$ \\
\hline
\end{tabular}

\section{Convergence study and validation}

Prior to the numerical simulations, the capture of wash wave pattern is validated against published simulation results. Convergence study is also performed to seek an appropriate configuration of the calculation parameter. Two types of the convergence verification are addressed with, namely the mesh convergence and the time step convergence.

\subsection{Validation}

Analytical approximation is available to estimate the wash wave load acting on the moored ship induced by another passing ship [23]. 


$$
\begin{aligned}
& F_{x}(d l, d t)=\frac{\rho u^{2}}{2 \pi} \int_{L_{2}} A_{2}^{\prime}\left(x_{2}\right) \int_{L_{1}} A_{1}^{\prime}\left(x_{1}\right) \frac{x_{1}-x_{2}+d l}{\left\{\left(x_{1}-x_{2}+d l\right)^{2}+d t^{2}\right\}^{1.5}} d x_{1} d x_{2} \\
& F_{y}(d l, d t)=\frac{\rho u^{2} d t}{\pi} \int_{L_{2}} A_{2}^{\prime}\left(x_{2}\right) \int_{L_{1}} A_{1}^{\prime}\left(x_{1}\right) \frac{1}{\left\{\left(x_{1}-x_{2}+d l\right)^{2}+d t^{2}\right\}^{1.5}} d x_{1} d x_{2}
\end{aligned}
$$

231 where $A_{i}$ is the section area of ship $i$ and $A_{i}$ is the sectional area slope. $d t$ is the lateral distance between 232 the two ships and $d l$ is their longitudinal distance. Please note that Eq. (16) is valid on condition that 233 the lateral distance $d t$ is small and the ship speed $u$ is not very high, since wave elevation effect is 234 neglected. As shown in Fig. 10, the wave load acting on a moored Wigley ship (Ship_1) induced by another identical Wigley ship (Ship_2) with speed $u$ is calculated by the present simulation tool, and will be compared with Eq. (16) for validation. The main dimensions of the two Wigley ships are identical to those presented in Table 1.

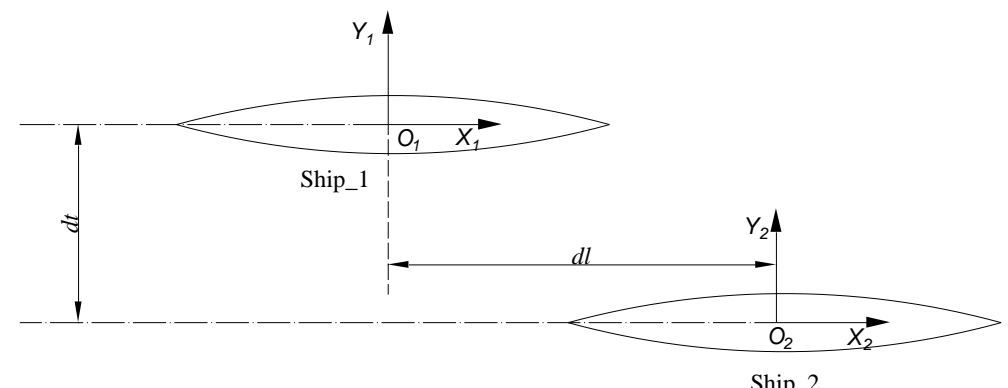

Fig. 10. Sketch of ship-to-ship interaction.

240 Fig. 11 plots the time series of the wave load acting on the moored ship during the passing process.

241 The longitudinal distance $d l$ is negative when the passing ship is behind the moored ship, and positive 242 when the passing ship is in front of the moored ship. Some slight discrepancies are observed since Eq. 243 (16) neglects the wave elevation effect whereas the wave disturbance at the free water free is considered 244 in the present model. 

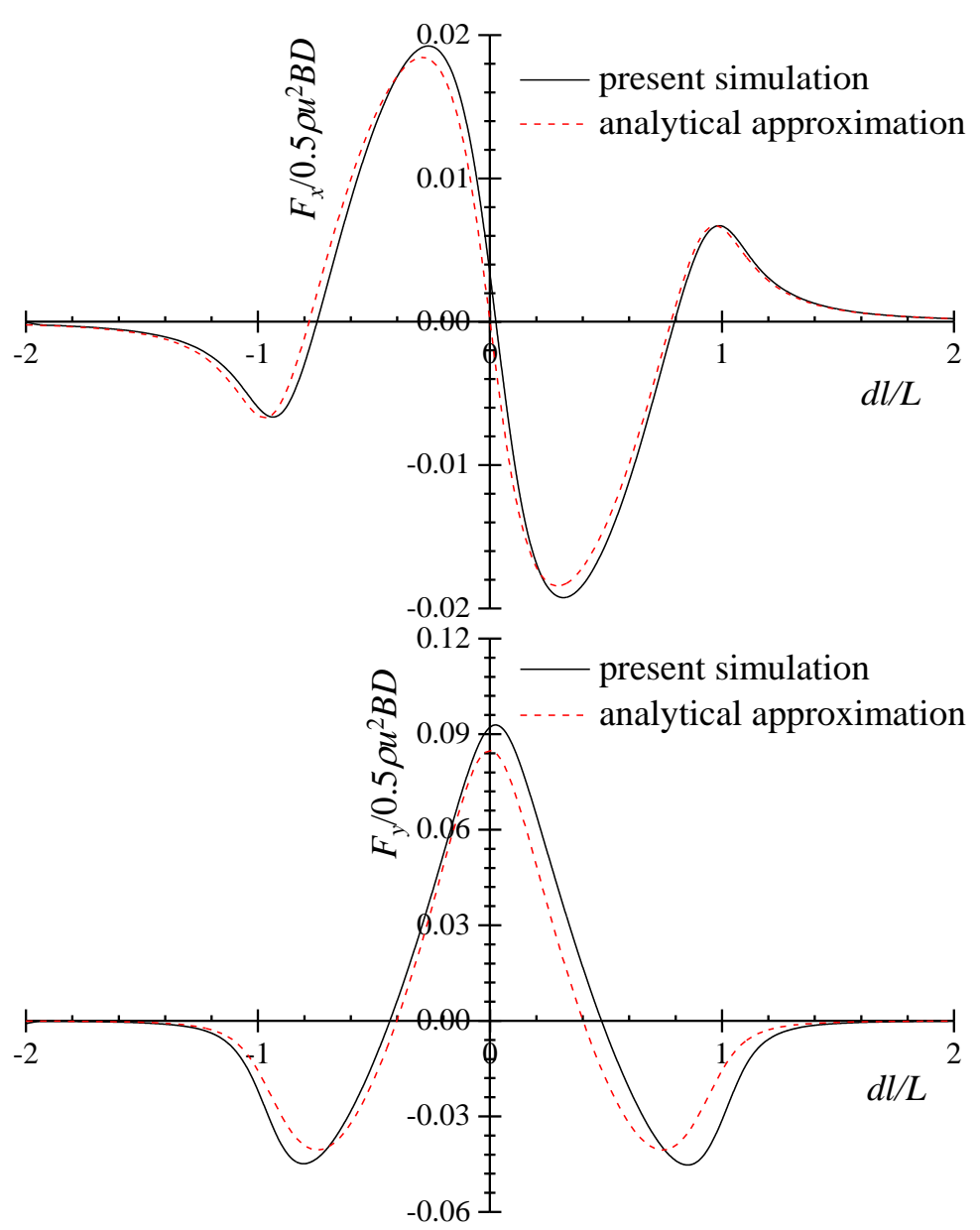

Fig. 11. Time series of hydrodynamic forces acting on the moored ship, $d t=1.5 B, u_{1}=3.6 \mathrm{~m} / \mathrm{s}, u_{2}=0 \mathrm{~m} / \mathrm{s}$. (a) longitudinal force; (b) lateral force.

248 The simulation results given by Jason et al. [24] are used here to check whether the present 249 simulation tool is able to capture the far-field wash wave pattern. A combined Rankine/Kelvin source 250 method was developed in [24], where the near-field and far-field wash waves were computed by the 251 higher-order Rankine source and the Kelvin source, respectively (see Fig. 12). Fig. 13 shows the far252 field wash waves produced by a sailing Wigley ship in open calm water with forward speed $F n=0.316$ 253 ( $F n=u / \sqrt{g L}, L$ is the ship length). Considering that the far-field wash wave was calculated with the 254 Kelvin source [24] whereas the present model uses the linear Rankine source, the agreement is 255 acceptable. 


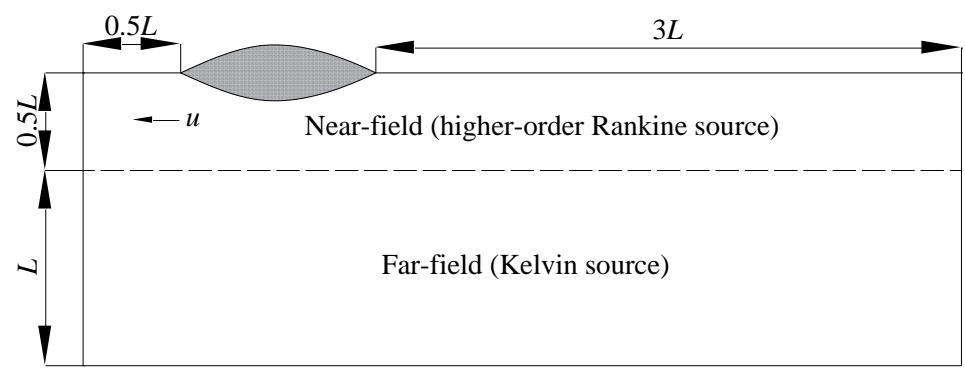

$\mathrm{a}$

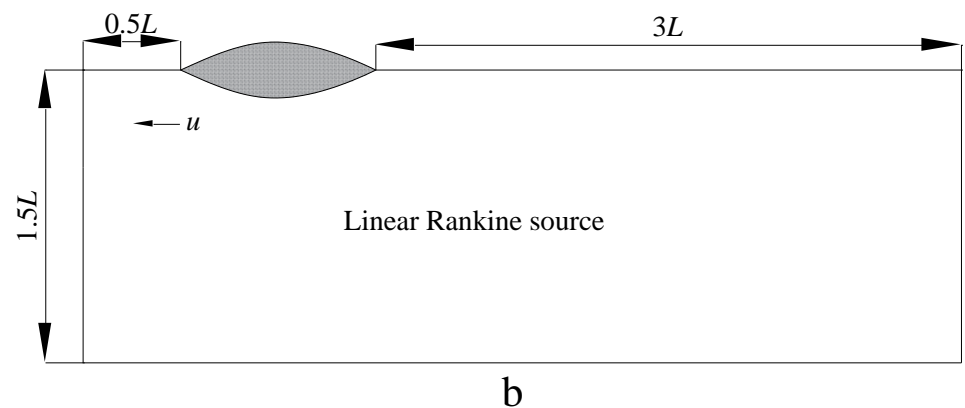

Fig. 12. Source distribution on the free surface. (a) Jason et al. [24]; (b) the present simulation.

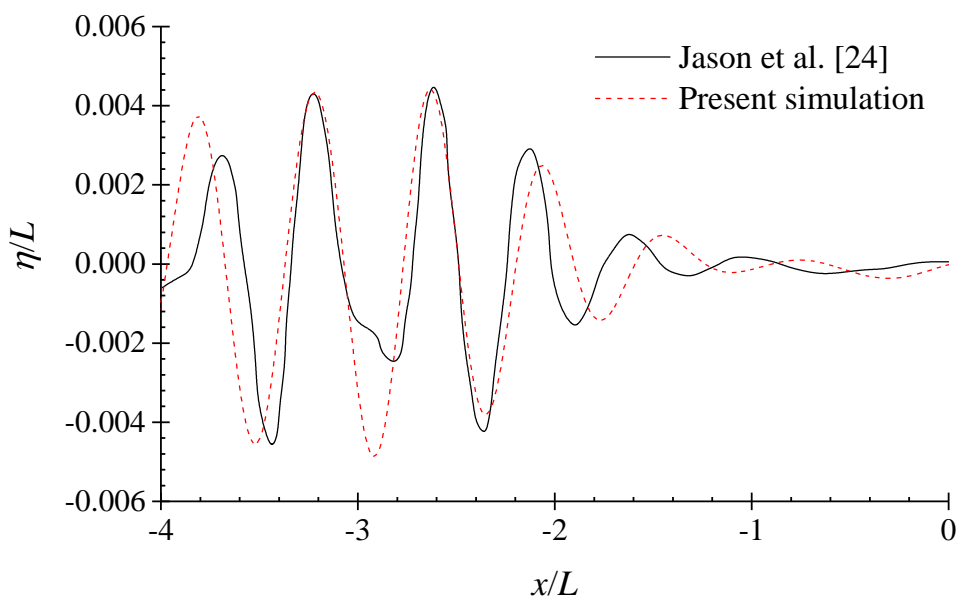

Fig. 13. Validation of wash wave cut at $y=0.75 L, F n=0.316$.

\subsection{Convergence study}

261 In this subsection, convergence study is conducted to investigate the effects of mesh size and 262 simulation step time. Fig. 3 shows the arrangement of the two ships. The distance between the two ships 263 are $40 \mathrm{~m}$ and the speed of the passing ship is $F n=0.8$.

264 Two sets of meshes are generated on the free surface and the ship hull. The fine mesh size is $2 \mathrm{~m} \times$ $2651 \mathrm{~m}(d x \times d y, d x$ is the mesh length along $X$ axis, and $d y$ is the mesh length along $Y$ axis), and the 266 standard mesh size is $2 \mathrm{~m} \times 2 \mathrm{~m}$. The wash wave force acting on the moored ship obtained with the two sets of meshes are compared in Fig. 14, where a good agreement is observed. 


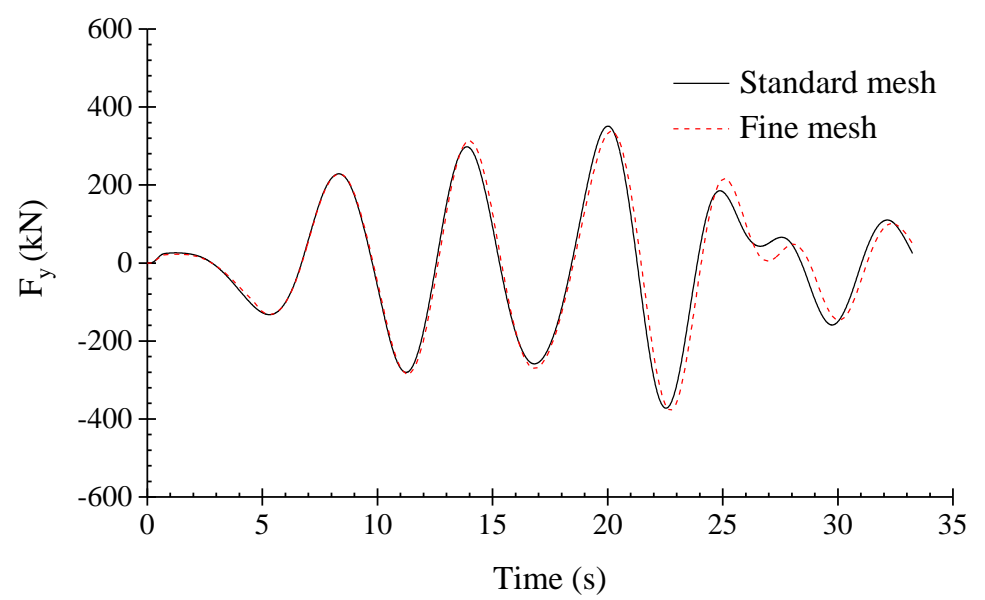

Fig. 14. Time series of sway wash wave force.

Time step convergence study is conducted because ship-passing-ship is by nature a moving boundary value problem and it is why the boundary formula is solved at each time step alongside with the update of free water surface. If the time step is too large then the calculation may become unstable and some critical times may be missed. Similarly, a fine time step $(\Delta t=0.5 \cdot d x / u)$ and a standard time step $(\Delta t=d x / u)$ are set respectively. Fig. 15 demonstrates the dependence of wash wave forces on the time step $\Delta t$. The two configurations of time step produce very similar estimations of the wash wave force.

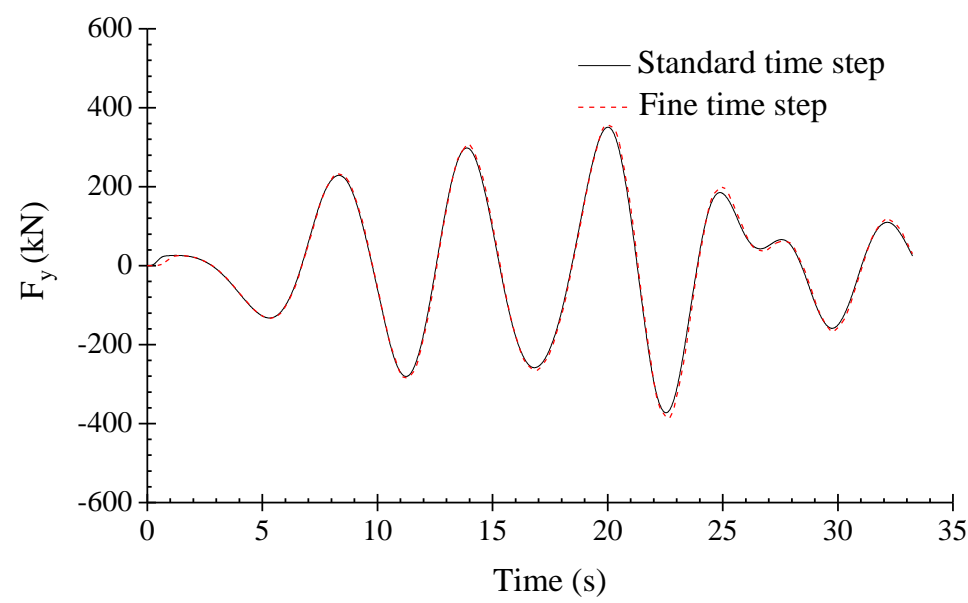

Fig. 15. Time series of sway wash wave force.

Based on the convergence study, the standard mesh and the standard time step can acquire satisfactory calculation accuracy. Therefore, the standard configurations of mesh and time step are used in the following part.

\section{Transient response induced by wash waves}

Based on the hybrid numerical model presented in Section 2, this section will examine the transient response of the moored ship induced by the wash wave impact loads. The environmental conditions considered in the simulations are listed in Table 4. The simulation runs 400 seconds in each load case, and the wash waves arrive the moored ship at $t=200 \mathrm{~s}$. The simulation time step is set to $0.01 \mathrm{~s}$. 
Table 4. Environmental conditions

\begin{tabular}{ccccccc}
\hline & $T p(\mathrm{~s})$ & $H s(\mathrm{~m})$ & $\beta$ & $F n$ & $d t(\mathrm{~m})$ & Wave condition \\
\hline C1 & - & - & - & 0.8 & 40 & wash wave \\
C2 & 9 & 0.3 & $150^{\circ}$ & 0.8 & 40 & wash wave + irregular sea wave \\
C3 & 8 & 0.2 & $90^{\circ}$ & 0.8 & 40 & wash wave + regular sea wave \\
C4 & 10 & 0.2 & $90^{\circ}$ & 0.8 & 40 & wash wave + regular sea wave \\
C5 & 14 & 0.2 & $90^{\circ}$ & 0.8 & 40 & wash wave + regular sea wave \\
C6 & 8 & 0.2 & $150^{\circ}$ & 0.8 & 40 & wash wave + regular sea wave \\
C7 & 8 & 0.2 & $90^{\circ}$ & 0.8 & 60 & wash wave + regular sea wave \\
C8 & 8 & 0.2 & $90^{\circ}$ & 0.6 & 40 & wash wave + regular sea wave \\
C9 & 8 & 0.2 & $90^{\circ}$ & 0.5 & 40 & wash wave + regular sea wave \\
\hline
\end{tabular}

288

\subsection{Transient responses in calm water}

290 Fig. 16 displays the wash wave pattern throughout the passing process without the presence of sea waves. When the wash waves reach the port bank, they are reflected and propagate back to the transverse wave region. On the contrary, the wash waves on the other side are free to propagate outward.

293 Three stages are identified during the passing process. In the first stage, the V-shape wash wave have

294 not arrived the moored ship yet, so that the near-field water surface around the moored ship is still. As

295 the passing ship continues advancing ahead, the moored ship enters the divergent wave region. It can

296 be seen that the divergent wash waves are reflected at the starboard of the moored ship, implying that

297 the moored ship is subject to the wash wave impact load. Finally, the divergent wave region passes by

298 the ship in which stage the ship is surrounded by the transverse waves and the reflected divergent waves. 


\section{a}
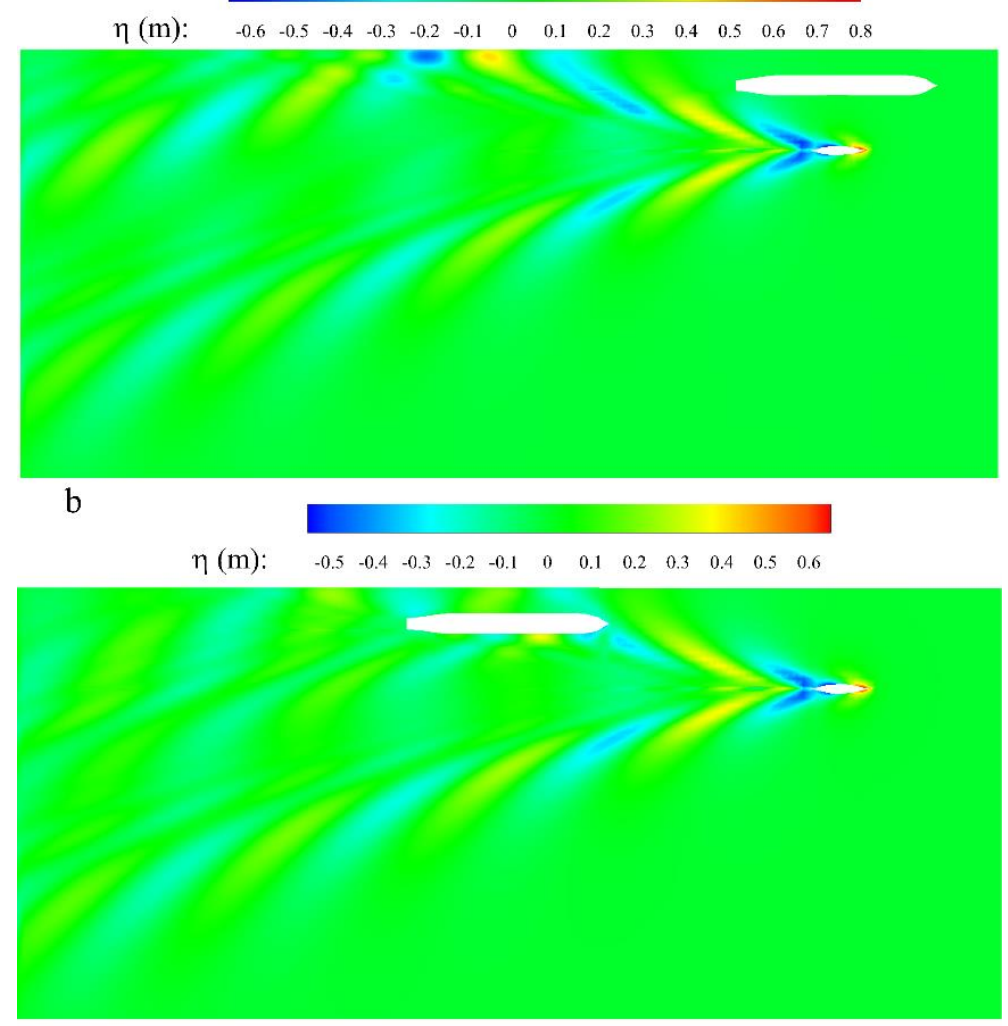

c

$\eta(\mathrm{m}):$

$\begin{array}{lllllllllllll}-0.6 & -0.5 & -0.4 & -0.3 & -0.2 & -0.1 & 0 & 0.1 & 0.2 & 0.3 & 0.4 & 0.5 & 0.6\end{array}$

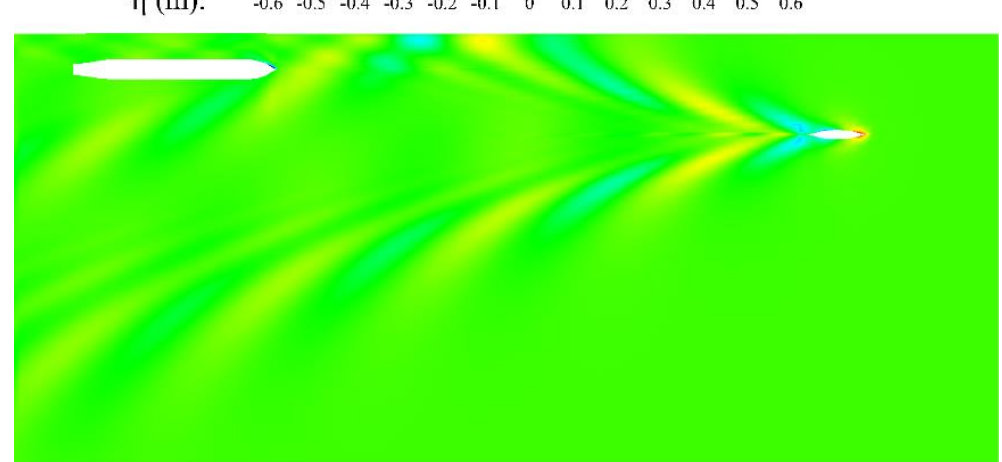

Fig. 16. Wash wave patterns (displayed in the body-fixed coordinate system), C1. (a) $t=200 \mathrm{~s}$; (b) $t=211.6 \mathrm{~s}$; (c) $t=223.3$ S.

Fig. 17 plots the transient motions of the moored ship induced by the wash waves alone. When the wash waves reach, the moored ship is subject to impact load immediately. Typical decay-type responses are observed. After that, the ship decays gradually since the wash wave region has overtaken the moored ship. Due to the pre-tension of the hawsers, the mean sway position is non-zero. 

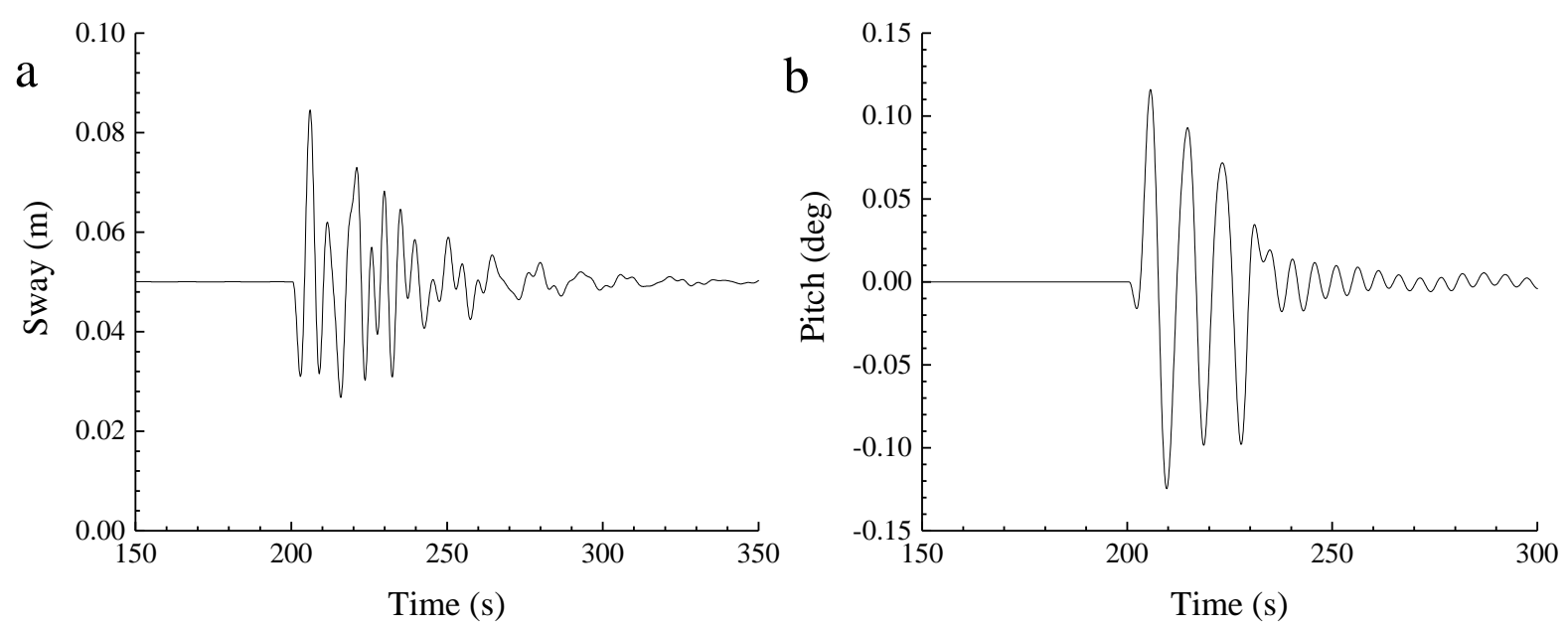

Fig. 17. Time series of ship motions, C1. (a) sway motion; (b) pitch motion.

Transient effect is also observed in the fender compression force. As shown in Fig. 18, the compression force is initially stable at $200 \mathrm{kN}$ to resist the pre-tension of the hawsers. During the transient stage, the fender also experiences decay-type response and returns to the initial state finally.

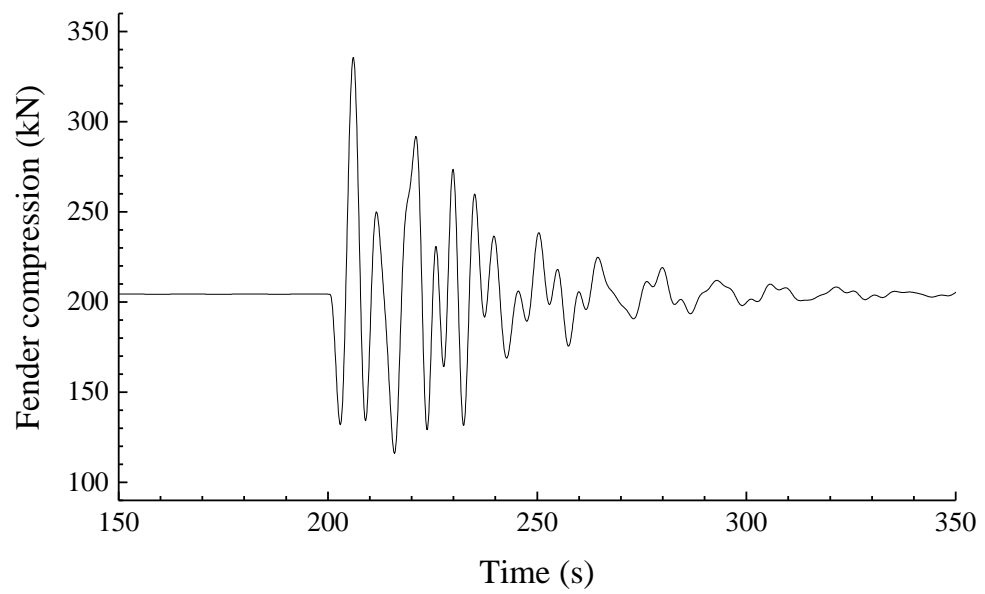

Fig. 18. Time series of fender compression, $\mathrm{C} 1$.

\section{2. $\quad$ Transient response in irregular sea waves}

Fig. 19 displays the time series of ship motions under joint action of sea waves and wash waves. When the wash waves arrive, the surge motion increases obviously. During the subsequent duration, an obvious long period surge motion induced by the wash wave impact loads is observed. On the contrary, the transient effect on roll motion is not very observable. It is difficult to identify the transient motion from the time series. To figure out the ship motions in wash waves and stochastic sea waves, the time series of transient motions (from $200 \mathrm{~s}$ to $300 \mathrm{~s}$ ) are analysed with fast Fourier transform (FFT) method to acquire the response spectrum. As shown in Fig. 20 (a), the surge motion is mainly stimulated at two frequencies. The major peak is found at $0.025 \mathrm{~Hz}$, corresponding to the natural period of surge motion. It is consistent with the time series of surge motion, which is dominated by the long period response. Besides, a minor response peak at $0.11 \mathrm{~Hz}$ (the significant period of sea waves) is observed. Apparently, the response within this range is produced by the incident sea waves. Similar response feature is 
identified in Fig. 20 (b). Nevertheless, a third response peak is found at $0.18 \mathrm{~Hz}$. According to Fig. 14,

326 the variation period of the wash wave impact loads is roughly $5 \mathrm{~s}$. It indicates that the third response 327 peak is stimulated by the wash waves.
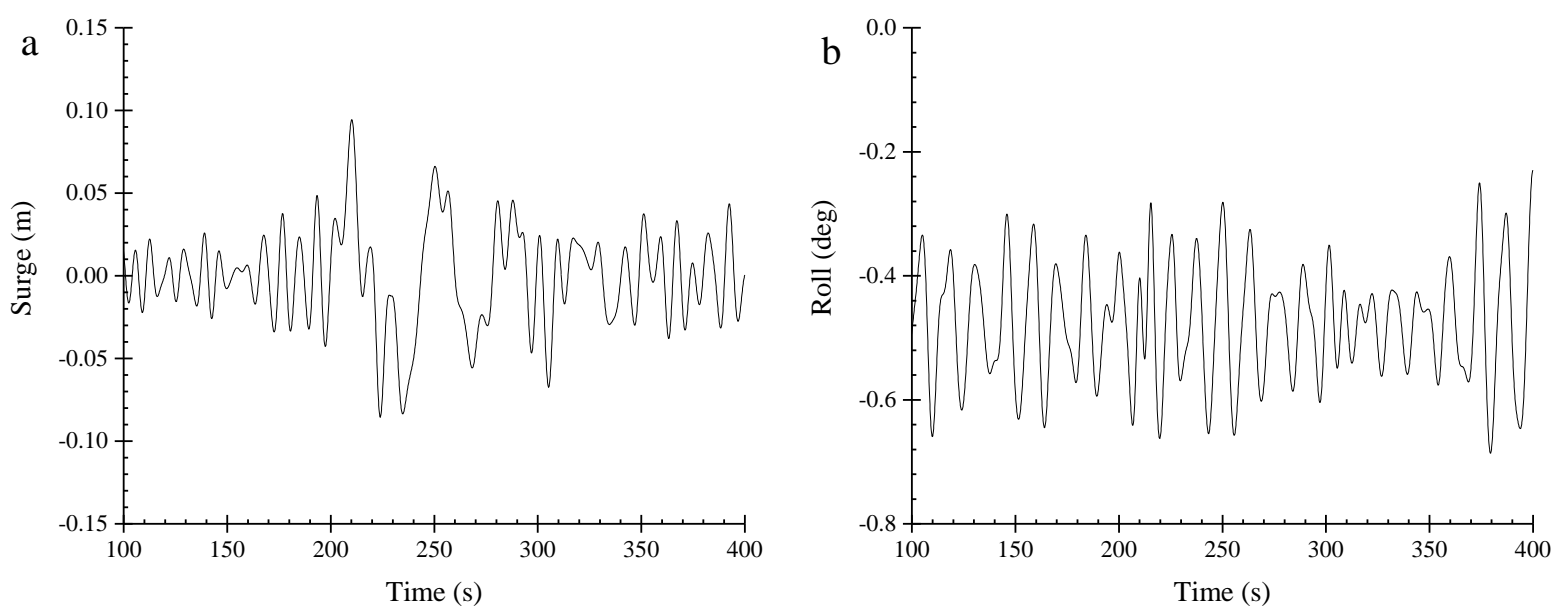

Fig. 19. Time series of ship motions, C2. (a) surge motion; (b) roll motion.
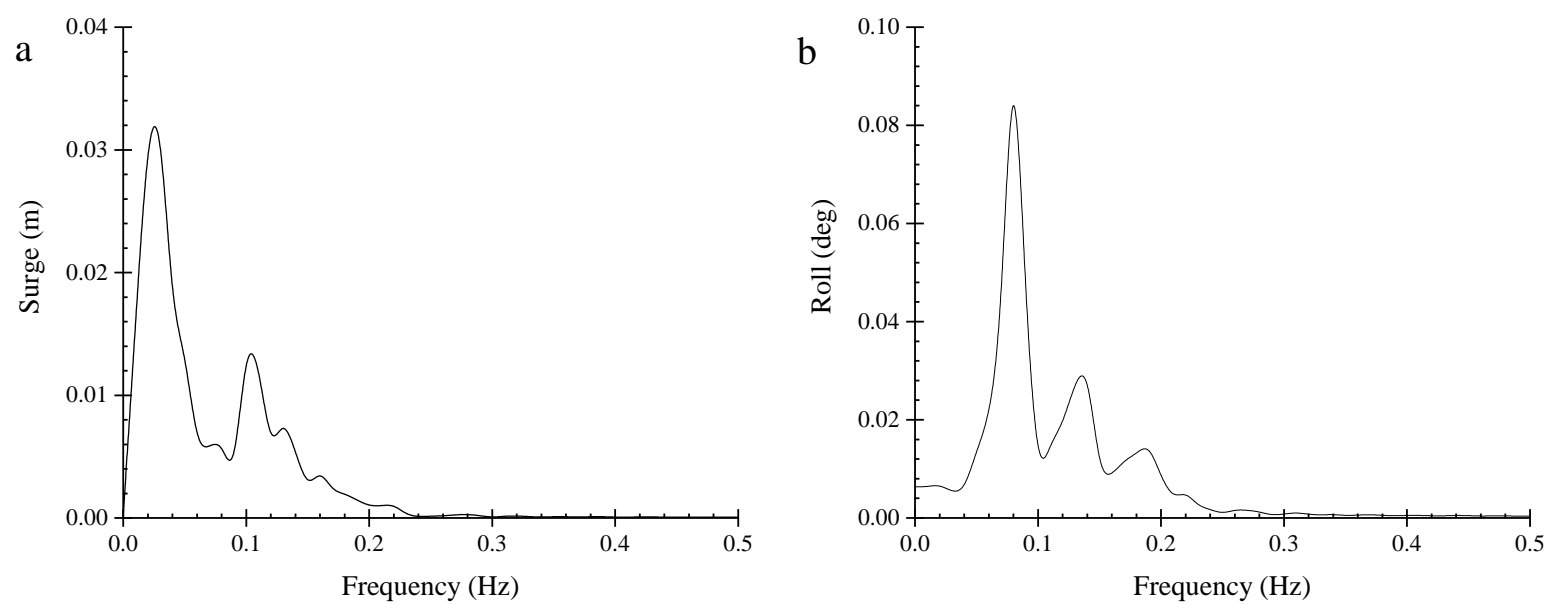

330

Fig. 20. Response spectrum of ship transient motions, C2. (a) surge motion; (b) roll motion.

Fig. 21 displays the time series of hawser 1 tension force. Once the ship is subjected to the wash waves, the mooring line tension varies violently and an obvious long period response can be identified. The FFT analysis results in Fig. 22 show a substantial response around the surge natural period, indicating that the resonant surge motion causes the hawser tension force. Additionally, sea waves induced response is identified around $0.12 \mathrm{~Hz}$ as well. The varying frequency of wash wave impact loads is also seen in the response of hawser tension force. The FFT analysis results show that the wash waves excite the resonant response of ship motions and decay-type motion will appear. The varying frequency of wash wave force can also be identified in the transient response. 


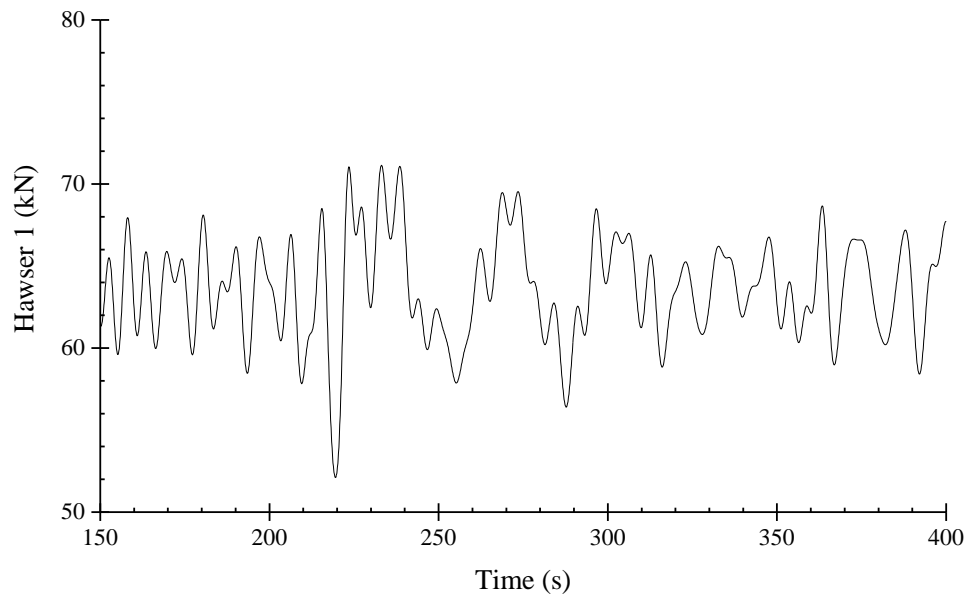

Fig. 21. Time series of hawser 1 tension force, C2.

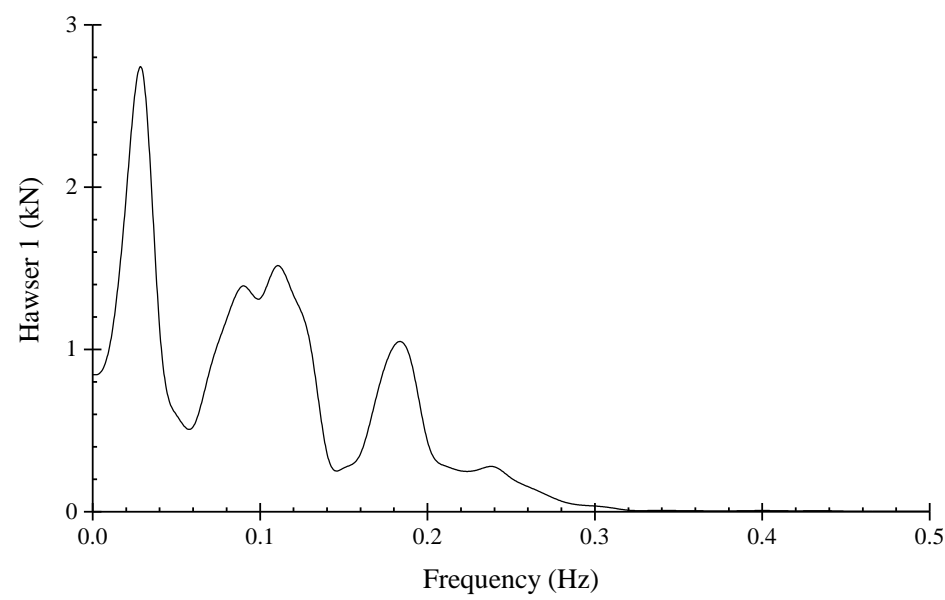

Fig. 22. Response spectrum of hawser 1 tension force, $\mathrm{C} 2$.

\subsection{Transient responses in regular waves}

This subsection will investigate how the sea wave condition, the wash wave propagation distance and the passing ship speed influence the transient responses of the moored ship. Since the transient responses induced by the wash waves are more observable when the sea waves are monochromatic, regular sea waves are selected in this subsection.

\subsubsection{The influence of sea waves}

Fig. 23 displays the transient motions of the moored ship in regular waves. Under pure sea wave excitation, the ship motions are steady-state and sinusoidal. Due to the pre-tension of the hawsers, the mean roll position is not $0 \mathrm{deg}$. When the wash waves arrive, transient effect arises due to the impact loads produced by the wash waves. During the transient duration, the ship motions transfer to unsteadystate and the response amplitudes increases accordingly. The transient effect on pitch motion is the most significant. The sea waves induced pitch motion is nearly invisible since the sea waves angle is $90^{\circ}$. Once the wash waves arrive, the pitch motion increases substantially and a decay-type motion is observed. The transient effect on sway motion is limited mainly attributed to the large stiffness of the fender, which absorbs the wash wave impact loads. 

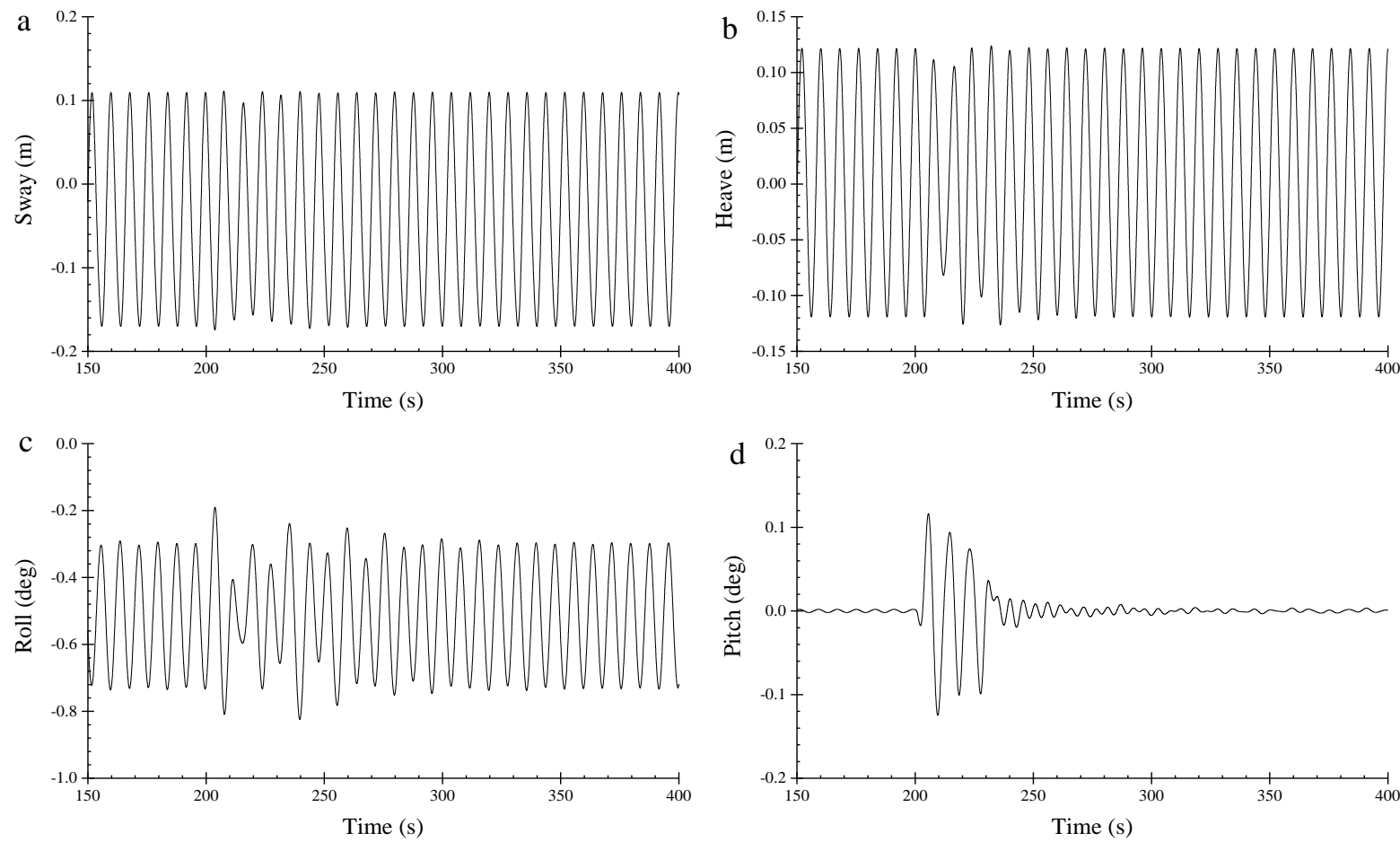

Fig. 23. Time series of ship motions in C3. (a) sway motion; (b) heave motion; (c) roll motion; (d) pitch motion.

Since the ship is subjected to sea wave forces and wash wave forces in the transient stage, it can be assumed that the transient effect will become less significant if the sea wave forces are larger. According to the sea wave force response amplitude operator (RAO) shown in Fig. 24, the transient effect on roll motion should be the least pronounced in simulation case C3. However, the time series of roll motion shows the opposite results. Although the sea wave forces are the largest in simulation case $\mathrm{C} 3$, the transient effect is nevertheless the most significant (see Fig. 25). Therefore, the transient effect should be independent from the sea wave force amplitude.

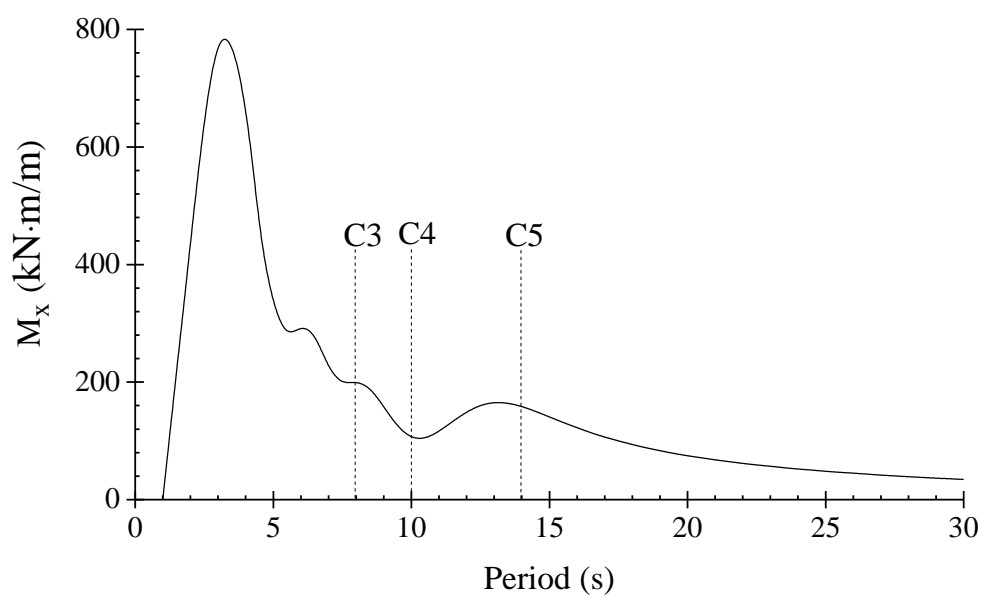

Fig. 24. RAO of roll wave moment. 

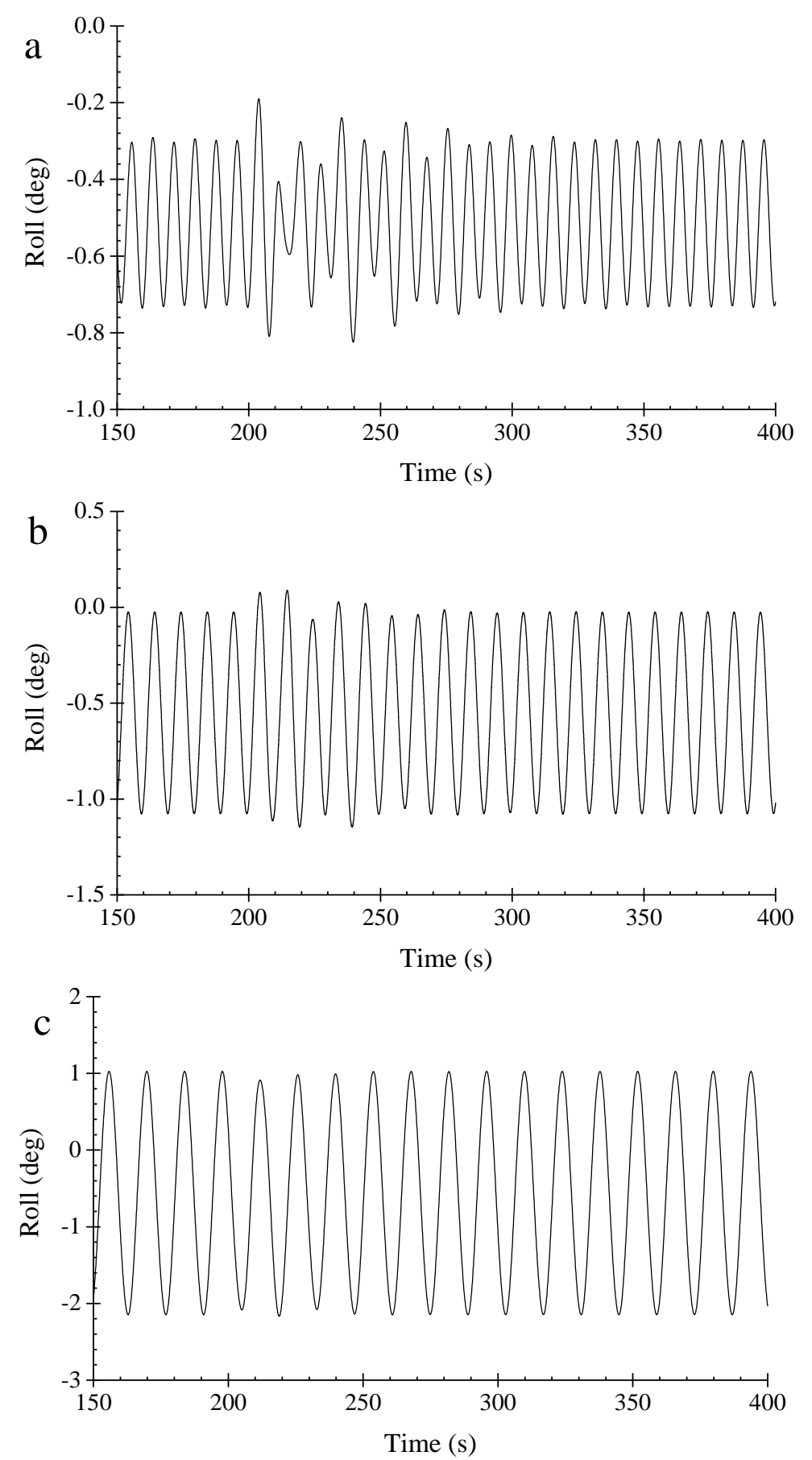

Fig. 25. Times series of ship roll motions. (a) C3; (b) C4; (c) C5.

Fig. 26 shows how the transient motions vary with the sea wave heading angle. When the sea wave heading angle changes from $90^{\circ}$ to $150^{\circ}$, the steady-state motion amplitudes for sway, heave and roll modes are all reduced. At the same time, the transient effects become increasingly observable with the reduction of steady-state motions. On the contrary, the transient effect on pitch motion becomes less pronounced. It seems that the transient effect depends on the sea waves produced motions. When the sea waves produced motions are strong, the transient effect tends to be limited and vice versa. 

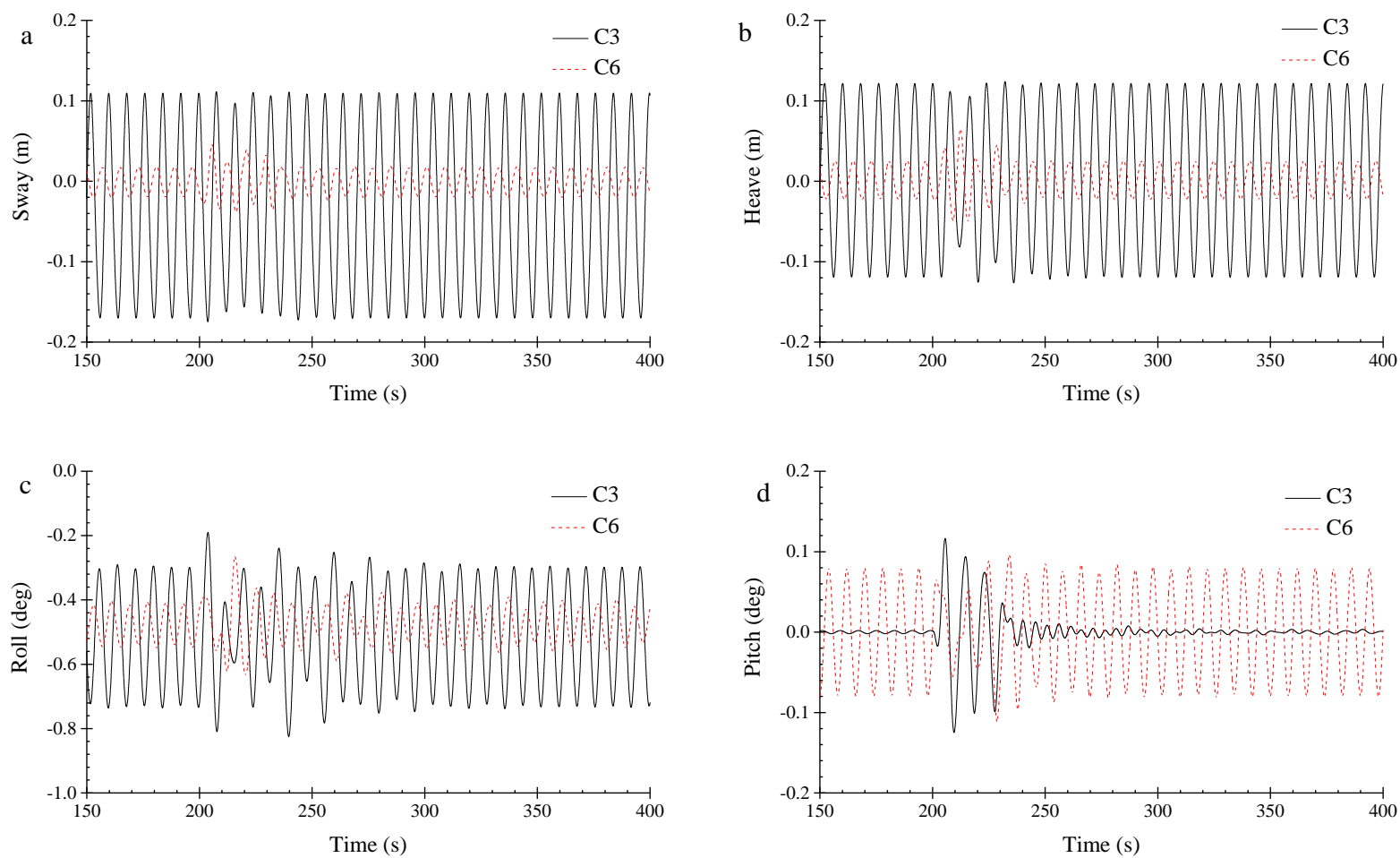

Fig. 26. Time series of ship motions. (a) sway motion; (b) heave motion; (c) roll motion; (d) pitch motion.

Apart from the ship, the hawsers are also subjected to wave impact loads (Please refer to Table 3 and Fig. 9 for the arrangement of hawsers). The tensions are likely to exceed the breaking values if the ship transient movement is too large. Fig. 27 shows the mooring line tensions when the wash waves arrive the ship. The maximum tension force of hawser 3 is $75 \mathrm{kN}$ and it jumps to $85 \mathrm{kN}$ subjected to the wash waves. The transient effect seems to be more observable on the tension of hawser 3 . According to the figuration of the mooring system (see Fig. 9), hawser 2 mainly bears the loads along $Y$ direction. The wash wave impact is mostly offset by the fender (see Fig. 28) and impact load transferred to hawser 2 is limited.

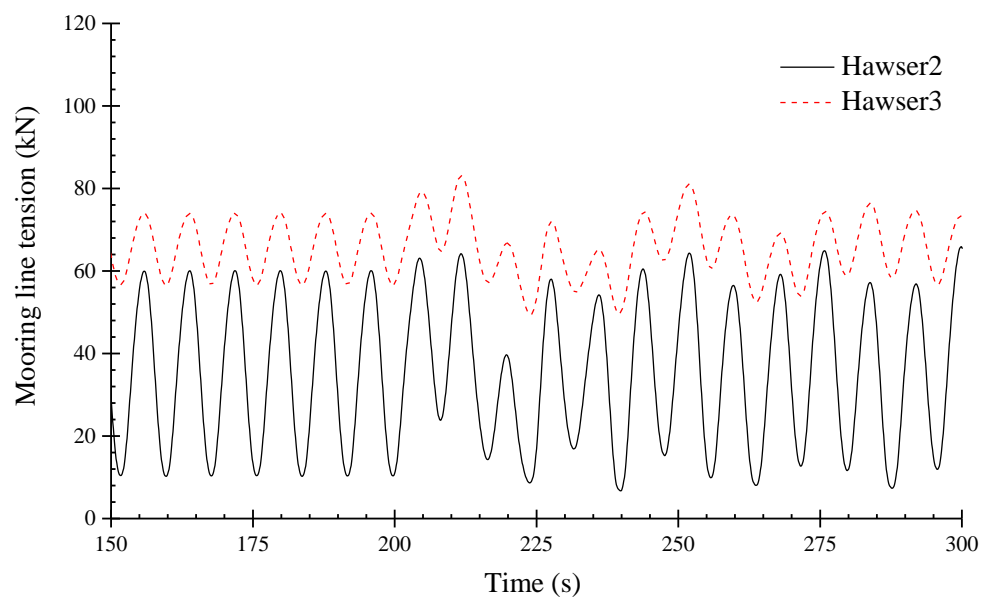

Fig. 27. Time series of hawsers tensions, C3. 


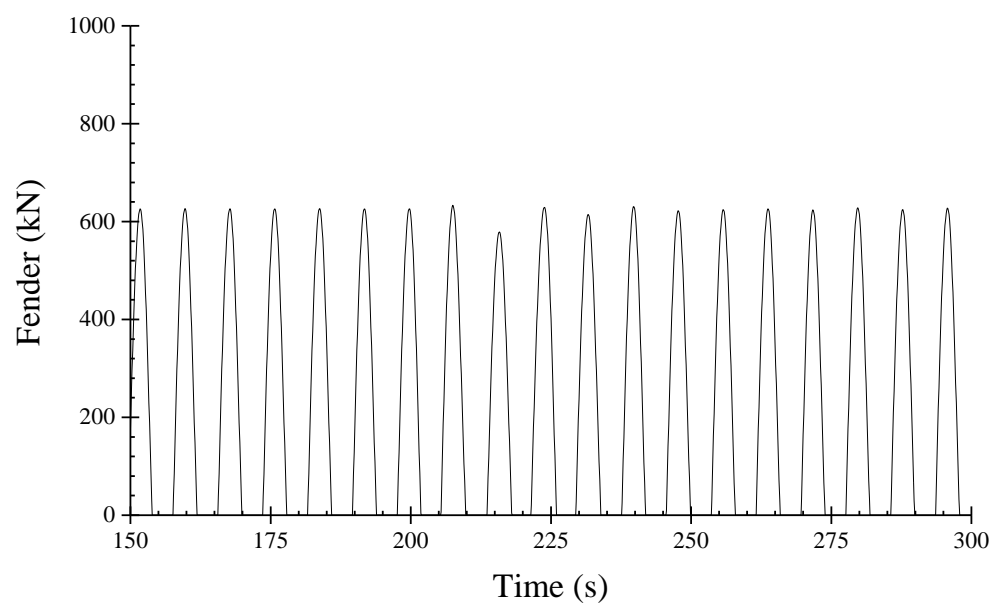

Fig. 28. Time series of fender force, C3.

\subsubsection{The influence of wash waves propagation distance}

The influence of wash waves propagation distance on the transient response is investigated by increasing parameter $d t$ from $40 \mathrm{~m}$ to $60 \mathrm{~m}$ so that the wash waves will travel another $20 \mathrm{~m}$ to reach the moored ship. Fig. 29 displays the transient ship motions with different propagation distances. As shown, the characteristics of the two curves are very similar. The ship motions reach peak values at identical times regardless of the propagation distance. It seems that the propagation of the wash waves has a tiny influence on the ship transient motions.
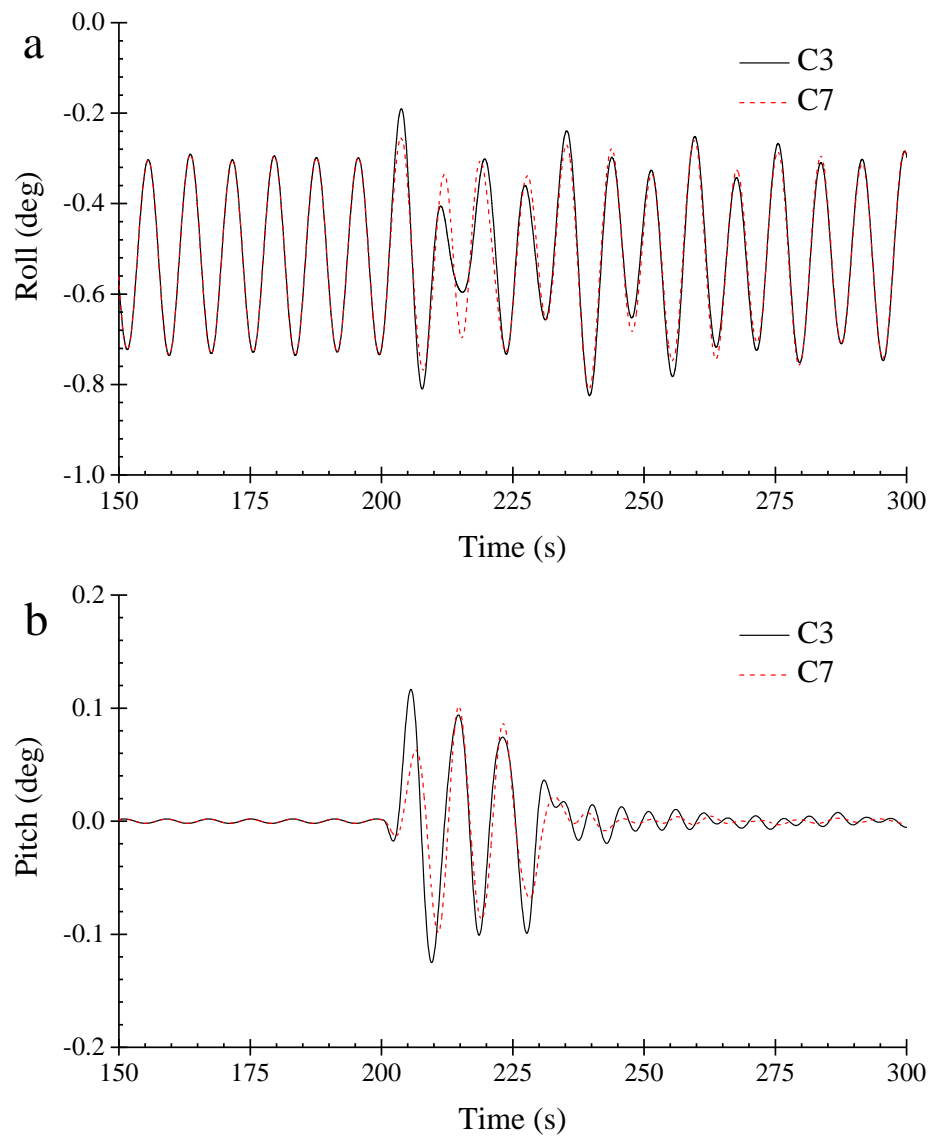

transient effect does not decrease obviously with the propagation distance.

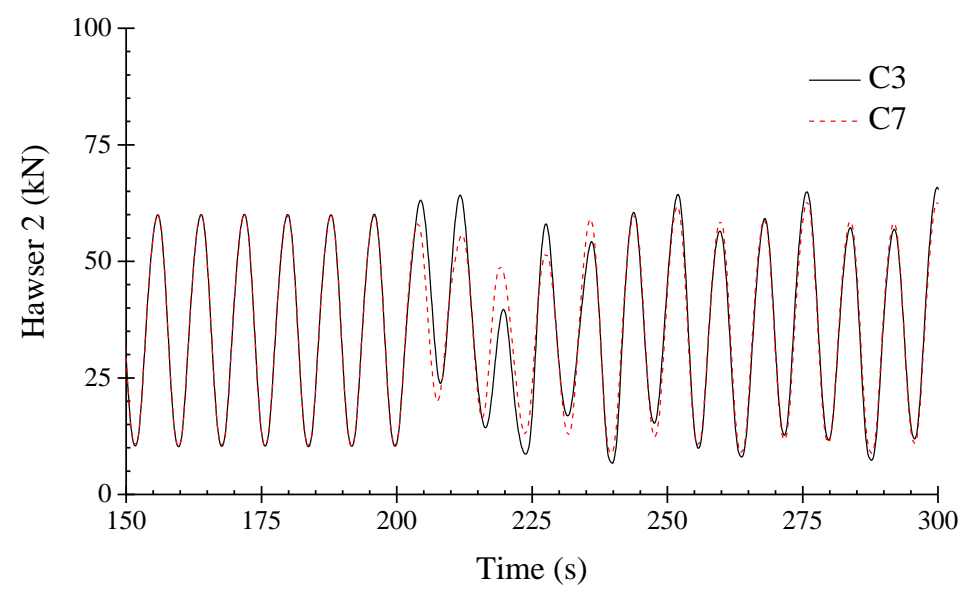

Fig. 30. Time series of hawser tensions with various lateral distances.

The propagation distance effect on the transient response is tiny, since the divergent wash waves dissipate little during the propagation process. Fig. 31 compares the wash wave patterns and Fig. 32 shows the near-field wave elevation at the starboad of the moored ship (along the black line in Fig. 31), when the divergent waves just arrive the bow of the moored ship. It is shown that the wave patterns are similar and the divergent waves hardly dissipate even if travel a longer distance. Therefore, the transient responses in the two cases are similar to each other.
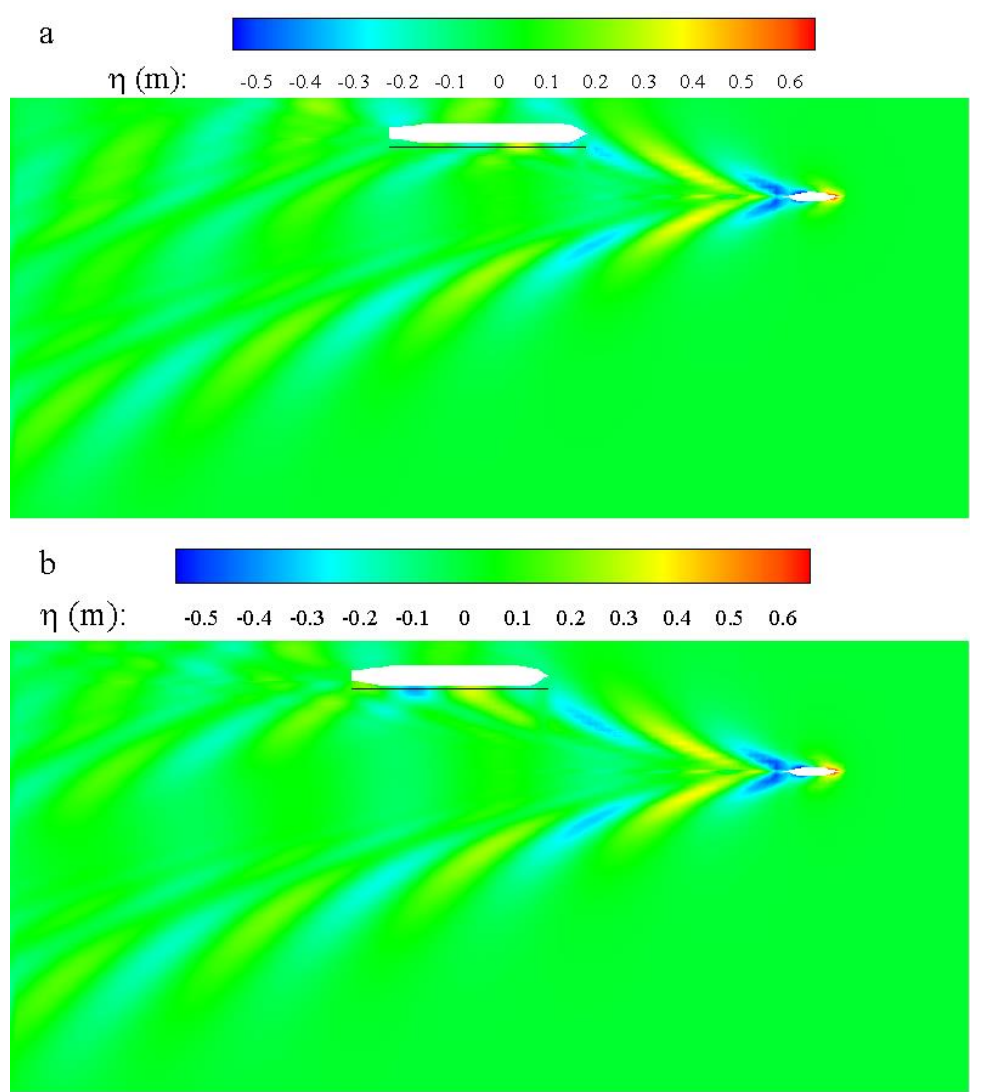

Fig. 31. Wash wave pattern with different propagation distances (displayed in the body-fixed coordinate system). (a) $d t=40$ $\mathrm{m}(\mathrm{C} 3)$; (b) $d t=60 \mathrm{~m}(\mathrm{C} 7)$. 


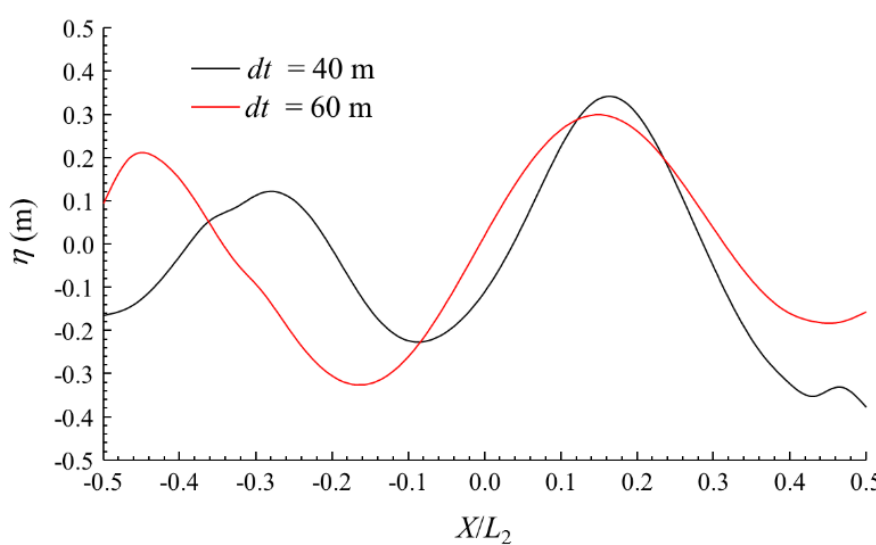

Fig. 32. Near-field wave elevation at the starboard of the moored ship.

416 5.3.3. The influence of passing ship speed

417 The ship motions with different passing ship's forwards speeds are compared in Fig. 33. As forward 418 speed of the passing ship drops, the transient ship motions reduce accordingly. The transient pitch 419 amplitude in simulation case C3 is over 0.1 deg whereas this value drops to below 0.02 deg when the 420 passing ship is travelling with $F n=0.5$. It is straightforward to understand such variation trend as the 421 wash wave elevation drops if the forward speed becomes smaller. The divergent wash waves are very 422 limited for low Froude number condition, in which case the energy is mainly carried by the transverse waves. 

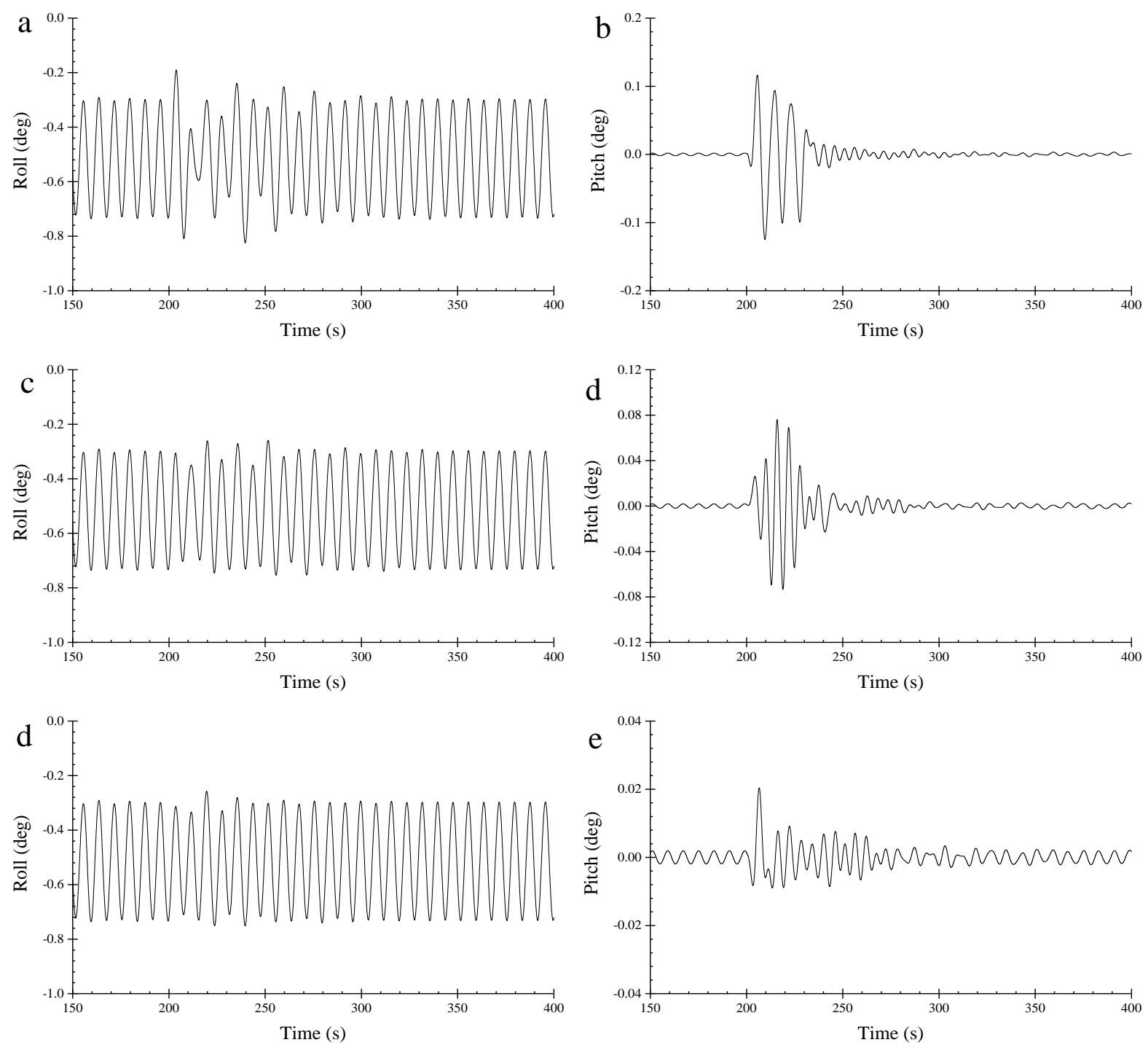

Fig. 33. Times series of ship motions at different forwards speeds. (a) C3, roll motion; (b) C3, pitch motion; (c) C8, roll motion; (d) C8, pitch motion; (e) C9, roll motion; (d) C9, pitch motion.

\section{Conclusions}

A hybrid numerical model based on 3-D Rankine source method and impulse response theory is developed to address the transient response of a moored ship under sea waves and wash waves produced a passing ship. The wave-structure interaction is firstly simulated with the 3-D Rankine source method. Afterwards, a time-domain analysis is performed to simulate the transient response of the moored ship.

The moored ship is subjected to significant wash wave impact loads even if the passing ship is travelling far away. Obvious transient effect is observed in ship motions and mooring line tensions. Decay-type response is observed during the transient duration.

The transient effect is associated with the sea waves induced response. When the sea waves induced response is strong, the transient effect tends to be limited and vice versa. The propagation distance of wash waves seems to have little influence on the transient response. The transient response is sensitive to ship speed. Fast passing ship induces strong transient response of the moored ship. 


\section{Acknowledgements}

440 This work was supported by China Scholarship Council [Grant No. 201506230127]. The authors are 441 grateful for their financial support.

\section{References}

443 [1] Kwak M, Moon Y, Pyun C. Computer simulation of moored ship motion induced by harbor 444 resonance in Pohang New Harbor. Coastal Engineering Proceedings. 2012;1:68.

445 [2] Sakakibara S, Kubo M. Characteristics of low-frequency motions of ships moored inside ports and 446 harbors on the basis of field observations. Mar Struct. 2008;21:196-223.

447 [3] Rosa-Santos P, Taveira-Pinto F, Veloso-Gomes F. Experimental evaluation of the tension mooring 448 effect on the response of moored ships. Coast Eng. 2014;85:60-71.

449 [4] Xiong LZ, Lu HN, Yang JM, Zhao WH. Motion responses of a moored barge in shallow water. $450 \quad$ Ocean Eng. 2015;97:207-17.

451 [5] Bingham HB. A hybrid Boussinesq-panel method for predicting the motion of a moored ship. Coast 452 Eng. 2000;40:21-38.

453 [6] van der Molen W, Wenneker I. Time-domain calculation of moored ship motions in nonlinear waves. 454 Coast Eng. 2008;55:409-22.

455 [7] Jiang T, Henn R, Sharma SD. Wash waves generated by ships moving on fairways of varying 456 topography. 24th Symposium on Naval Hydrodynamics, Fukuoka, Japan2002. p. 441-57.

457 [8] Vantorre M, Verzhbitskaya E, Laforce E. Model test based formulations of ship-ship interaction 458 forces. Ship Technology Research. 2002;49:124-41.

459 [9] Mousaviraad SM, Sadat-Hosseini SH, Stern F. Ship-ship interactions in calm water and waves. Part 460 1: Analysis of the experimental data. Ocean Eng. 2016;111:615-26.

461 [10] Brix J. Manoeuvring Technical Manual. Schiff und Hafen. 1987;36.

462 [11] Wang QX. An analytical solution for two slender bodies of revolution translating in very close 463 proximity. J Fluid Mech. 2007;582:223-51.

464 [12] Pinkster JA. Suction, Seiche, and Wash Effects of Passing Ships in Ports. Proceedings of the 465 Annual Meeting of the Society of Naval Architects and Marine Engineers (SNAME). Providence,2009. 466 p. 99.

467 [13] Yuan ZM, He S, Kellett P, Incecik A, Turan O, Boulougouris E. Ship-to-Ship Interaction during 468 Overtaking Operation in Shallow Water. J Ship Res. 2015;59:172-87.

469 [14] Xu H, Zou Z. Prediction of hydrodynamic forces on a moored ship induced by a passing ship in 470 shallow water using a high-order panel method. Journal of Shanghai Jiaotong University (Science). $471 \quad 2016 ; 21: 129-35$.

472 [15] Yuan ZM, Incecik A, Alexander D. Verification of a new radiation condition for two ships 473 advancing in waves. Appl Ocean Res. 2014;48:186-201. 
474 [16] Cummins W. The impulse response function and ship motions. Washington DC: David Taylor 475 Model Basin; 1962. p. 101-9.

476 [17] Longuet-Higgins MS, Cokelet ED. The deformation of steep surface waves on water. I. A 477 numerical method of computation. Proceedings of the Royal Society of London A: Mathematical, 478 Physical and Engineering Sciences: The Royal Society; 1976. p. 1-26.

479 [18] Xu H, Yue D. Computations of fully nonlinear three dimensional water waves. Proceedings of the 480 19th Symposium On Naval Hydrodynamics. Seoul, Korea1992.

481 [19] Bunnik THJ. Seakeeping calculations for ships, taking into account the non-linear steady waves. 482 Delft, Netherlands: Delft University of Technology; 1999.

483 [20] Zhang XS, Bandyk P, Beck RF. Time-Domain Simulations of Radiation and Diffraction Forces. J 484 Ship Res. 2010;54:79-94.

485 [21] Zhang XS, Bandyk P, Beck RF. Seakeeping computations using double-body basis flows. Appl 486 Ocean Res. 2010;32:471-82.

487 [22] Hall M, Goupee A. Validation of a lumped-mass mooring line model with DeepCwind 488 semisubmersible model test data. Ocean Eng. 2015;104:590-603.

489 [23] Varyani KS, Krishnankutty P. Modification of ship hydrodynamic interaction forces and moment 490 by underwater ship geometry. Ocean Eng. 2006;33:1090-104.

491 [24] Janson CE, Leer-Andersen M, Larsson L. Calculation of deep-water wash waves using a combined 492 Rankine/Kelvin source method. J Ship Res. 2003;47:313-26. 